\begin{tabular}{|c|l|}
\hline Title & Construction and pavement properties after seven years in porous asphalt with long life \\
\hline Author(s) & Moriyoshi, A kihiro; Jin, Toshiro; Nakai, Takaaki; Ishikawa, Hiroshi; Tokumitsu, Katsuy a; Kasahara, A kihiko \\
\hline Citation & $\begin{array}{l}\text { Construction and Building Materials, 50, 401-413 } \\
\text { https://doi.org/10.1016/.Conbuildmat.2013.09.023 }\end{array}$ \\
\hline Issue Date & $201401-15$ \\
\hline Doc URL & http://hdl.handle.net/2115/54105 \\
\hline Type & article (author version) \\
\hline File Information & CBME.pdf \\
\hline
\end{tabular}

Instructions for use 


\title{
[Short paper]
}

\section{Construction and pavement properties after seven years in porous asphalt with long life}

\author{
Akihiro Moriyoshi \\ Division of Urban and Environmental Engineering, Graduate School of Engineering, \\ Hokkaido University, North 13 West 8, Kita-ku, Sapporo, 060-8628, JAPAN
}

Current affiliation and address :

Material Science Laboratory

Hokkaido University Emeritus Professor

2-1-9-10, Kiyota, Kiyota-ku, Sapporo, 004-0842, JAPAN

Tel/Fax : +81 11882 4246, E-mail : moriyoshi@cap.ocn.ne.jp

Toshiro Jin

Kyoto Prefectural Road Public Corporation

Kyoto Fucho West Building, Agaru Simodachiuri,

Nishinotouin Street, Kamigyo-ku, Kyoto, 602-8054, JAPAN

Current affiliation and address :

Kyoto Prefectural Road Public Corporation

Kyoto Fucho West Building, Agaru Simodachiuri,

Nishinotouin Street, Kamigyo-ku, Kyoto, 602-8054, JAPAN

E-mail: t-jin@kyoto-ldpc.jp

Tel: +81 75431 4253, Fax: +81 754316870

Takaaki Nakai

Kyoto Prefectural Land Development Public Corporation

Kyoto Fucho West Building, Agaru Simodachiuri,

Nishinotouin Street, Kamigyo-ku, Kyoto, 602-8054, JAPAN 
Current affiliation and address :

Kyoto Prefectural Land Development Public Corporation

Kyoto Fucho West Building, Agaru Simodachiuri,

Nishinotouin Street, Kamigyo-ku, Kyoto, 602-8054, JAPAN

Tel: +81 75431 4157, Fax: +81 754513918

Hiroshi Ishikawa

Obayashi Road Corporation, Hokkaido Branch

Oak Sapporo Building 5 floor, West 2 North 1, Chuoh-ku, Sapporo, 060-0001, JAPAN

Current affiliation and address :

Obayashi Road Corporation, Hokkaido Branch,

Oak Sapporo Building 5 floor, West 2 North 1, Chuoh-ku, Sapporo, 060-0001, JAPAN

Tel/Fax : +81 11241 1828, E-mail : h-ishikawa@ obayashi-road.co.jp

Katsuya Tokumitsu

Division of Urban and Environmental Engineering, Graduate School of Engineering,

Hokkaido University, North 13 West 8, Kita-ku, Sapporo, 060-8628, JAPAN

Current affiliation and address :

Nippon Road Co., Ltd., Technical Research Institute,

2-11-20 Tamagawa, Ohta-ku, Tokyo, 146-0095, JAPAN

Tel: +8133759 4872, Fax: +81337592250

E-mail: katsuya.tokumitsu@nipponroad.co.jp

Akihiko Kasahara

Nippo Corporation, Business Head office, Research Institute

3-32-34 Higashi-Shinagawa, Shinagawa-ku, Tokyo, 140-0002, JAPAN

Current affiliation and address :

Nippo Corporation, Business Head office, General Technical Department,

Research Institute, 6-70 Mihashi, Nishi-ku, Saitama, 331-0052, JAPAN

Tel: +81 48624 0755, Fax: +81 486240797

E-mail: kasahara_akihiko@nippo-c.jp 
Corresponding author : Akihiro Moriyoshi

Material Science Laboratory

Hokkaido University Emeritus Professor

2-1-9-10, Kiyota, Kiyota-ku, Sapporo, 004-0842, JAPAN

Tel/Fax : +81 11882 4246, E-mail : moriyoshi@ cap.ocn.ne.jp

Keywords : Porous asphalt pavement, Factors for long life, Pavement properties after seven years, Kyoto Specifications, Relation between rut depth and temperature

Word count: 6,728 words (41,849 characters, included with space) (36 pages)

7 Tables and 13 Figures

\section{Abstract}

This paper describes the construction and pavement properties after seven years in porous asphalt with long life in Kyoto Jukan Expressway, comparing with conventional methods. It was constructed in 1998 in accordance with various kinds of specifications (Kyoto Specifications), regarding modified binder, aggregate, asphalt mixture, asphalt plant, construction machine and construction method. It consists of four different sections in pavement and they were constructed in order to aim the long life and to evaluate their effects on the life in porous asphalt. In this study, it was described construction and pavement properties including with effects of water content of materials on temperature in porous asphalt in Kyoto Jukan Expressway and relation 
between local rut depth and local cooling on surface after finishing in dense type mixture.

It was concluded that the long life in porous asphalt related to the quality of materials, uniformity of surface temperature after finishing, cubic stone in porous asphalt, and local temperature on pavement surface after finishing connected with local rut depth in dense type mixture.

\section{Introduction}

Generally, it has been common belief that the damages such as rutting and cracks in asphalt pavement occurred when ambient temperature changed [1 - 3]. Especially, it was said that it was very difficult to construct the pavement of long life in porous asphalt, because severe damages such as pothole and stripping of aggregate in porous asphalt occurred, and the causes of those damages after service in asphalt pavement were not yet clarified [4, 5]. But porous asphalt in Kyoto Jukan Expressway was maintenance free for fifteen years using Kyoto specifications, and pothole and stripping of aggregate in Kyoto Jukan expressway were not observed. Beside, aging of modified binder in Kyoto Jukan Expressway was not also observed, because the color of 
pavement surface on porous asphalt is held in real black and modified binder covered aggregate on pavement surface is not stripped for fifteen years.

Generally, on one hand, it has been believed that pothole and stripping of aggregate were caused by inappropriate technique in pavement construction, and appropriate construction methods have been pursued [6]. On other hand, we suppose that damages such as stripping of aggregate and pothole in porous asphalt were caused by the large strain due to movement of aggregate under moving load at high temperature $[7,8,9]$, and the those damages in porous asphalt were mainly caused by high void of mixture in local cooling points in porous asphalt just after finished.

This paper describes the construction included with the effect of water content in porous asphalt and pavement properties after seven years (the life for seven years was initially assumed) in Kyoto Jukan Expressway, comparing with conventional asphalt pavement [10] and relationship between local rut depth and local cooling in dense type mixture.

It was concluded that crack patterns in porous asphalt in Kyoto Jukan Expressway connected with properties of binder, type of crushed stones and pavement structure, and they were very important factors for long life in porous asphalt, and local temperature 
on pavement surface after finishing connected with local rut depth in dense type mixture.

\section{Outline of Kyoto Jukan Expressway}

Kyoto Jukan Expressway is located in mountainous area of northern Kyoto in Japan and the ambient temperature exceeds $30{ }^{\circ} \mathrm{C}$ in summer and it becomes $-10{ }^{\circ} \mathrm{C}$ for ten years and it also snows a lot in winter. It was required to hold the long life with seven years or more and no damage such as pothole or stripping of aggregate. Then the following innovative techniques for porous asphalt in those test sections were introduced firstly in Japan. They are very severe specifications, comparing with those of conventional porous asphalt in Japan [11]. Both specifications are shown in Table 1. New concepts in porous asphalt in Kyoto Jukan Expressway are as follows.

The four new items were required, firstly, to maintain uniformity of pavement material (shipment temperature in mixture and temperature of pavement surface just after finishing, water content of mixture, modified binder), secondly, to introduce the proper composition which has less movement of aggregate in mixture (good interlocking between aggregate), thirdly, to improve adhesion of binder (large strength and fracture strain of modified binder), lastly, to take counterapproach (new method for 
aging) in order to prevent deterioration of modified binder. Therefore, the Kyoto Specifications were newly specified to satisfy the above four items.

Kyoto Jukan Expressway was constructed in 1998 using those Kyoto Specifications and total length was $12.6 \mathrm{~km}$. In those sections, traffic volume per day has been anticipated two thousand vehicles /day /one lane after opening.

The actual test section in porous asphalt (surface course: $4 \mathrm{~cm}$, void ratio: $20 \%$ ) was divided into four test sections (Section A-1, Section A-2, Section X and Section B) as shown in Fig. 1. The almost section in Kyoto Jukan Expressway $(12.6 \mathrm{~km})$ was constructed in Section A-2. Whereas, Section $\mathrm{T}$ was not section and it was located in Section A-2 and it was a new sample just after completion. The thickness of binder course and asphalt treated base course were all the same in four sections (Table 2). Crushed stone in surface course in Section A-2, Section X and Section B was used in all the same type (selected hard sandstone and cubic type using Barmac crusher, water absorption: $0.45 \%$ ), but conventional crushed stone (local hard sandstone, water absorption: $0.98 \%$ ) was also used in Section A-1. Two types of binder were used in those sections, and Binder Type A in Section A-1, Section A-2, Section B and Binder Type B were used in Section X (Fig. 1). The characteristics of both modified binder in porous asphalt (surface course) satisfied with Kyoto specifications (described later). 
In this study, results for various tests after seven years in Kyoto Jukan Expressway and properties in hot mixture after construction were described.

\section{Three dimensional crack analyses}

Three dimensional crack analyses was used to evaluate the degree of damage using micro focus CT scanner (CT) and soft program (ExFact Analysis 2.0 for Porous/Particles, Nihon Visual Science Corporation) for the cored specimens taken from the four test sections after seven years in Kyoto Jukan Expressway.

The specimens for CT and three dimensional crack analyses with a size of $2.5 \mathrm{x}$ $2.5 \times 8 \mathrm{~cm}$ were cut from the each layer of sampled cores of ten centimeter. One thousand four hundred forty tomographic images of specimens in 16 bits grey scale with $512 \times 512$ pixels which size were $0.06 \times 0.06 \times 0.06 \mathrm{~mm}$ were taken by micro focus CT Scanner (inspeXio SMX-225CT, Shimadzu Corporation). The particle of the aggregate, the air voids and the complicated network structure of cracks were visualized as abstracted three dimensional model and the differences of thickness of cracks were shown in seven rainbow colors $[12,13]$. The width of four pixels, which was $0.24 \mathrm{~mm}$, could be detected stable based on the limit of resolution from the size of specimen of $2.5 \times 2.5 \times 8 \mathrm{~cm}$ and the imaging condition. 


\section{Material and innovative methods}

\subsection{Materials}

\subsubsection{Binder}

In order to satisfy Kyoto specifications in modified binder concerning anti-aging, anti-degradation, anti-low temperature cracking and good adhesion to aggregate, many times of trials were requested to refineries, and two special kinds of binders (Type A and Type B) from two different refineries were selected (Table 1).

\subsubsection{Binder's testing}

The properties and specifications for modified binder specified by Kyoto specifications were as follows and shown in Table 1, together with specifications in Japan $[14,15]$.

Main tests for modified binder are as follows.

1) High Temperature Long Time Durability Test (HTLTD Test, at $163^{\circ} \mathrm{C}$ for 72 hours, $\pm 1^{\circ} \mathrm{C}$ ) using Moriyoshi Breaking Point test (MBP, fracture strain: $0.3 \%$ ) was specified the lower than the lowest ambient temperature $\left(\mathrm{T}_{\mathrm{L}}\right)$ of the past decade in Kyoto region (lower than $\mathrm{T}_{\mathrm{L}}=-10^{\circ} \mathrm{C}$ ) in order to prevent thermal cracking at low temperature and to maintain degrading 
resistance of modified binder and to prevent the aging of modified binder for long time, to hold adhesion to aggregate of modified binder and to check the compatibility of modified binder [16].

2) The Fraass Breaking Point (FBP: $\pm 1^{\circ} \mathrm{C}$ ) after Thin Film Oven Test (TFOT) of 5 hours at $163^{\circ} \mathrm{C}$ was introduced and specified the lower than the lowest average daily temperature $\left(\mathrm{T}_{\mathrm{AV}}\right)$ in January in the region, which was $-4^{\circ} \mathrm{C}\left(\mathrm{T}_{\mathrm{AV}}=-4^{\circ} \mathrm{C}\right)$, and was specified to control quality of modified binder.

3) The tensile strength and failure strain of modified binder both at FBP and FBP $-10^{\circ} \mathrm{C}$ after TFOT of 5 hours at $163^{\circ} \mathrm{C}$ were specified more than $5 \mathrm{MPa}$ and $3,000 \times 10^{-6}(0.3 \%)$, respectively, to keep adhesion to aggregate and to suppress movement of aggregate under moving load [17].

4) Simplified One Minute MBP test was introduced in asphalt plant in order to check whether the delivered modified binder could pass the specifications (MBP) for original modified binder.

In plant, it was performed at $\mathrm{MBP}+1^{\circ} \mathrm{C}$ to check the quality (crack pattern and crack temperature) of modified binder.

The method of One Minute MBP test is as follows. 
$50 \mathrm{~g}$ of hot binder put into special made stainless vessel (diameter $14 \mathrm{~cm}$, depth

$1 \mathrm{~cm})$, which was taken directly from the top of a binder lorry for every delivery as a sample. It was ascertained whether crack occurred when the sample was immersed in methanol bath $\left(\mathrm{MBP}+1^{\circ} \mathrm{C}\right)$ for one minute.

\subsubsection{Aggregate}

Table 3 shows the characteristics of aggregate for porous asphalt used in Kyoto Jukan Expressway, together with the specifications in Japan, that were specified taking the following requirements into consideration, but characteristics of aggregate for surface course in dense type mixture used in Osaka in Japan were not shown in Table 3. The aggregate in Osaka consists of andesite type and it is usually used in Japan.

In Kyoto Jukan Expressway, the following three items were required. Firstly, the aggregate shall have good resistance to fracturing during compaction of asphalt mixture and secondly, it shall not chemically react with organic matters and lastly, it shall have long durability.

The air void of $20 \%$ in porous asphalt was specified to prevent from clogging and Barmac impact crusher was used to crush the selected aggregate. It could remove corner angle of aggregate which lead to produce cubically shaped aggregate 
(cubic stone) by impact crusher with centrifugal force. In addition, it was assumed that less movement and/or rotation of aggregate in mixture became by better interlocking of the aggregate in porous asphalt.

Considering of severe chemical and $\mathrm{X}$ ray analysis results, such as adhesion to binder, constituent in aggregate and capability to meet requirement of high volume production, which described later, it was selected excellent aggregate as porous asphalt for this project.

It was considered that the modification of aggregate shape could increase the size of air void in porous asphalt even if the percent of air void was still the same.

\subsubsection{Mixture}

The stripping test in various types of solution (Table 3) as chemical test in aggregate with modified binder according to test method (JPI-5S-27-86) of Japan Petroleum Institute was performed for new aggregate and new modified binder, and thereafter the combination of aggregate and modified binder was determined.

Table 4 shows the composition of selected mixture (Type A mixture) in the porous asphalt in Kyoto Jukan Expressway and the conventional composition (Type B 
mixture) in porous asphalt in Japan. The latter had been commonly used in Japan. Plant fiber (abocel: methyl cellulose type) was also added in Type A mixture to prevent segregation and binder drip in the porous asphalt mixture on cargo bed of dump truck during transportation. Anti-drip effect using abocel in Type A mixture was confirmed, but it was not used for mixtures in Type B, Type C and Type D in this study.

Table 5 shows the criteria in air void and tensile strength (splitting tensile strength) in porous asphalt mixture using Type A and Type B binder in Kyoto Jukan Expressway. They were strictly specified considering both drainage function, such as percent of air void and continuity of air void, and adherence property to prevent from stripping of aggregate, comparing with those of porous asphalt in Japan. It was considered to be important to specify percent of air void and splitting tensile strength at low temperature at $-25^{\circ} \mathrm{C}$ for $2 \mathrm{~cm}$ thickness specimens of upper and lower layer. They were cut from the surface course of $4 \mathrm{~cm}$ thickness, because void properties and strength of surface course might be changed by means of construction procedure. The splitting tensile test at $-25^{\circ} \mathrm{C}$ with loading rate of $50 \mathrm{~mm}$ per minute was introduced as an alternative test of real tensile test in Kyoto Jukan Expressway. Those values satisfied with Kyoto Specifications, so that it may connect to the long life in porous asphalt. 


\subsubsection{Pavement structure}

The pavement structure in four sections in Kyoto Jukan Expressway is shown in Table 2. Only surface course was used modified binder (Styrene Butadiene Co-polymer type) in all sections. Straight asphalt was used in binder course and asphalt treated base in all sections and those layers were constructed according to conventional specifications in Japan.

\subsection{Innovative methods}

In Kyoto Jukan Expressway, not only manufacturing method of asphalt mixtures in high quality but also the improvements of asphalt plant, construction method and construction machine were made in order to get much further quality of pavement.

Those improvements and methods of quality control in Kyoto Jukan Expressway are shown as follows.

\subsubsection{Manufacturing method in asphalt plant (Batch type)}

We found that stripping of aggregate in porous asphalt was observed as naked stone (modified binder could not observe around aggregate) after one month in service in porous asphalt in Hokkaido in Japan (water content of hot mixture at the field was $0.5 \%$ ).We suppose that it was caused by water in aggregate, because we confirmed 
large water content of aggregate $(0.32 \%)$ in porous asphalt affected to rut depth in our laboratory and it was easily stripped in solution of anion type surfactant $(0.5 \%)$ at $45^{\circ} \mathrm{C}$ under wheel tracking test of TRRL type. Then, the water content of mixture in porous asphalt was severely controlled in this project.

Then, the following six points were improved in this project.

\section{1) Improvement of the shape of impeller in dryer}

The shape of impellers inside of dryer was modified in order to reduce and keep homogeneity of water content in aggregate by means of letting residence time of aggregate in dryer be longer [18]. It was obtained by small steel elements which were attached in circular direction in dryer.

\section{2) Elimination of water vapor in heated aggregate}

Gas and/or water vapor was not usually released from dryer during heating of cold aggregate by sealed system in the current asphalt plant from the aspect of energy saving. Then, drying system of aggregate was improved in order to release water vapor in the heated aggregate.

\section{3) Improvement in stock yard of aggregate}

Usually, aggregate has been piled in outdoors so that water content would increase because of rainfall. In order to avoid adverse effects on aggregate 
from the rainfall, aggregate was stocked in rooms with roof and side walls [19] and the bed of stockpiles was made in tapered concrete to extrude the water.

\section{4) Temperature control of aggregate in hot bins}

The hot bins were equipped on the mixing apparatus (mixer) and all aggregate, which was transported by elevator from dryer, was sieved at each size through vibrating screen on the mixer. It was assumed that water content in aggregate of large size was not dried the inside of aggregate and the temperature of aggregate in hot bin one $(0-2.5 \mathrm{~mm})$ and hot bin three $(5-13 \mathrm{~mm})$ after heating depended upon the water content of cold aggregate before heating. Therefore, the temperature of aggregate in hot bin one and hot bin three was compared with water content before and after radiation by microwave of 500 watt for ten minutes for aggregate of $200 \mathrm{~g}[20,21]$.

\section{5) Stirring apparatus in binder storage tank at asphalt plant}

In Kyoto Jukan Expressway, the modified binder was beforehand with segregation using HTLTD test. But if binder stored in asphalt tank at asphalt plant at $150^{\circ} \mathrm{C}$ for a long time, the constituent in straight asphalt and modified binder would easily segregate. Then, a stirring apparatus in the binder storage tank was introduced to prevent the segregation of modified binder, because the 
SBS in modified bitumen, which specific gravity was smaller than conventional binder.

\section{6) Quality of modified binder at every delivery of binder by tank lorry}

It was already confirmed that quality of binder varies widely every day by Fraass Breaking Point (FBP) test and Moriyoshi Breaking Point (MBP) test, even if the same type binders were refined and delivered from the same refinery [22]. Then, the quality of modified binder was checked by On Minute MBP test at plant. If thermal crack $\left(\mathrm{MBP}+1^{\circ} \mathrm{C}\right)$ in One Minute MBP test was observed in sample, it was specified to refuse the delivery in order to maintain the good quality in modified binder.

\subsubsection{Construction}

\subsubsection{Time of construction}

Usually, asphalt pavement has been constructed in all season in Japan. However, considering on effect of compaction and local cooling of hot mixture and adhesive property to the lower layer, the time of construction in porous asphalt in Kyoto Jukan Expressway was limited only in summer time when the ambient temperature was higher than $25^{\circ} \mathrm{C}[23]$. 


\subsubsection{Construction machine}

Asphalt finishers and compacting rollers at certain points were attached with hoods in order to prevent local cooling in hot mixture. Asphalt finisher was also modified to prevent segregation in hot mixture. By attaching the insulation to the asphalt finishers, the local cooling in hot mixture was prevented. It was prohibited to use detergent which has been used as anti-adhesive agent during compaction.

\subsubsection{Dump truck in transportation of hot mixture}

Usually, conventional dump trucks (capacity: 10 ton) which transport aggregate without insulation are used for transportation of hot mixture in Japan, so that local cooling of mixture cannot be prevented. Two layers of plywood in concrete formwork, which each thickness of $12 \mathrm{~mm}$, were set on all platforms and side walls of the dump trucks under transportation (maximum time: thirty minutes) so that the local cooling in hot mixture could be prevented. It was very effective to prevent local cooling of mixture under transportation. 
It has been also found that if there was a temperature difference more than $15^{\circ} \mathrm{C}$

on the surface of pavement during construction using conventional noncontact thermometer, the density and air void in dense type mixtures varied [24]. So that, the criteria of temperature difference within $15^{\circ} \mathrm{C}$ was specified. The two kinds of noncontact thermometer were used to check the temperature difference during construction. One was placed in a gondola in height of $5 \mathrm{~m}$ and the other was set on a car which traveled together with asphalt finisher side by side. Consequently, the average temperature difference in all test sections in porous asphalt was $8.1^{\circ} \mathrm{C}$.

\subsubsection{Construction joint of porous asphalt}

Hot joint method was introduced to avoid the longitudinal construction joint and to ensure a good bond at the joint by operating two finishers of same type with the same performance side by side [25].

\subsection{Investigations in asphalt plant (Batch type)}

\subsubsection{Asphalt plant}

The variation for temperature and water content of materials using Type A and Type B binder are shown in Table $6[26,27]$. They were obtained according to 
above innovative techniques in asphalt plant. It was confirmed that the temperature and water content of materials in porous asphalt were almost homogeneous in Kyoto Jukan Expressway.

\subsection{Investigations under and after construction}

Table 7 shows the test results after completion and under construction in Kyoto Jukan Expressway. The results for many tests almost satisfied with the limit of specifications in Kyoto Jukan Expressway. Especially, the average temperature just after finishing was $8.1^{\circ} \mathrm{C}$ and the value did not exceed $9{ }^{\circ} \mathrm{C}$ in all sections.

\subsection{Investigations in the field at seven years}

The followings tests for porous asphalt at seven years after construction in the four test sections were performed to examine the cause of long life in Kyoto Jukan Expressway. The three dimensional crack analyses were also performed for cored specimens and acceptable limit for each test was also shown.

\subsubsection{Smoothness of the pavement in the longitudinal direction}


It was measured using a three meter profile meter. The standard deviation was between $0.77 \mathrm{~mm}$ and $1.01 \mathrm{~mm}$ at Inner Wheel Path (IWP) in all the test section. They were smaller than acceptable limit of 4 - $5 \mathrm{~mm}$ in Japan.

\subsubsection{Roughness on pavement in transverse direction using JHS 225}

The roughness on pavement surface between inner white line and outer white line in transverse direction at twenty locations were measured by a transverse profile meter (length: $3 \mathrm{~m}$, minimum rut depth: $0.1 \mathrm{~mm}$ ) using Japan Highway Standard (JHS225)[28]. The all results were fallen into the acceptable level of $2.4 \mathrm{~mm}$.

\subsubsection{Skid resistance by a dynamic coefficient of friction}

The skid resistance was measured by a DF tester to obtain the dynamic coefficient of friction $(\mu)$ specified in the book of the separate volume of pavement manual in Japan. The test was made by moving vehicle of eighty kilometer per hour at twenty locations of Outer Wheel Path (OWP). The results were between 0.48 and 0.52 . They were larger than acceptable limit of 0.4 in Japan.

\subsubsection{Water permeability test in the field using JHS 233}


The test was performed by the time of water flow from water of $400 \mathrm{cc}$ in a cylinder using Japan Highway Standard (JHS 233) at OWP and Between Wheel Path (BWP) of twenty locations. All of the results fell into from 4.48 seconds to 6.72 seconds. Those values satisfied the criteria $(<10$ seconds) in JHS 233 in Japan.

\subsubsection{Water permeability test in laboratory}

The twenty four specimens which were taken from IWP and BWP of the test sections were tested indoor. All of the results were fallen into from $1.7 \times 10^{-2}$ to $4.3 \times 10^{-2} \mathrm{~cm} / \mathrm{sec}$. . Those values satisfied the criteria $\left(>10^{-2} \mathrm{~cm} / \mathrm{sec}\right)$ in JHS 233 in Japan.

The tests for stripping of aggregate, cracking, aging and pothole were not performed in this study, but those damages were not observed in four sections for fifteen years.

\subsection{Three dimensional crack analyses after seven years}

The distributions of three dimensional cracks in porous asphalt for initial condition, type of crushed stone, concrete slab were shown in Fig. 2 - Fig. 5 and those images 
were expressed in transversal side. Binder and base were expressed binder course, asphalt treated base course, respectively and the void ratio was measured by micro focus CT scanner. It happens to obtain the same values in maximum crack width $(1.2 \mathrm{~mm})$ in all Figures.

\subsubsection{Initial condition}

Fig. 2 shows the distribution of three dimensional cracks, maximum width of crack (mm) and void ratio (\%) in Section A-2 and Section T. The specimen in Section T was the same as Section A-2, but it was taken from new porous asphalt in Section A-2 in Kyoto Jukan Expressway (Fig. 1).

It can be seen that the air void (cracks) and the continuity in Section A-2 (after seven years) did not change for seven years, comparing with that of Section T (Initial condition), because the relatively thick cracks (green) connected continuously from surface to bottom.

The crack patterns in both sections were almost the same one. It means that the crack patterns in Section A-2 did not change from initial condition, because aggregate in Section A-2 did not move in service.

\subsubsection{Influence of crushed stones}


Fig. 3 shows that the distribution of three dimensional cracks, maximum width of crack (mm) and void ratio (\%) in each layer in the Section A-2 (cubic stone) and Section A-1 (conventional stone). Those figures were shown to compare the crack patterns for type of crushed stone in both sections. Relatively wider cracks (green) in Section A-2 connected continuously from surface to bottom, comparing with those patterns in Section A-1. Whereas, the air void in the surface course in Section A-1 decreased from $20 \%$ to $14.7 \%$ due to movement of aggregate in Section A-1 for seven years. It can be seen that discontinuity of the air void (short line: green) appeared by clogging in the middle of the path of the air void, because of consolidation of surface course. In addition, Fig. 3 shows that there were many cracks of $0.72 \mathrm{~mm}$ width indicated in yellow color in the top half part of the asphalt treated base course and the fatigue failure in the bottom half part was also observed. Even if the composition in both mixtures were the same in four sections, there were many cracks in Section A-1. But, the smoothness of the pavement in transverse direction after seven years in Section A-1 was as the same value as the Section A-2. It was considered that the influence of the movement and/or rotation of the aggregate in porous asphalt mixture (surface course) in Section A-1, by the traffic load under the high ambient temperature, had reached to the 
under layers of surface course. On the contrary, the number of cracks (red) did not increased in Section A-2.

It was considered that the modified cubic shape of aggregate and the discontinuous graded composition in porous asphalt led to the result of less movement and/or rotation of aggregate by moving vehicle, because of better interlocking of aggregate.

\subsubsection{Porous asphalt on concrete slab}

Fig. 4 shows distribution of three dimensional cracks, maximum width of crack $(\mathrm{mm})$ and void ratio $(\%)$ in Section A-2 and Section B (pavement on concrete bridge). Both composition, type of crushed stone and properties of binder were the same, but many cracks were observed in Section B, especially in binder course. There are many cracks with yellow $(0.72 \mathrm{~mm})$ and red $(0.24 \mathrm{~mm})$ color in Section B. It means that those cracks were induced by movement of aggregate in porous asphalt, but there are many green $(0.96 \mathrm{~mm})$ and yellow $(0.72 \mathrm{~mm})$ color in Section A-2.

It may be caused by the larger elasticity coefficient in underlying layer (concrete slab).

It seems that the damage of asphalt pavement on concrete bridge was larger than that of standard section (Section A-2). 


\subsubsection{Influence of binder types}

Fig. 5 shows distribution of three dimensional cracks, maximum width of crack $(\mathrm{mm})$ and void ratio (\%) in Section A-2 (Type A binder) and Section X (Type B binder). Section $\mathrm{X}$ was also used cubic type of aggregate, but both properties of binder which were satisfied with Kyoto Specifications, were different from each other. Crack patterns in both sections were similar with each other, but there are many wider cracks (green) in Section A-2, comparing with those patterns in Section X. Yellow and red color of cracks in Section X means that initial crack width decreased with time. But, the void ratios in Section $\mathrm{X}$ and Section A-2 were the same value as initial void ratio $(20 \%)$

Fig. 6 shows the void ratio in each layer in all four sections after seven years. It shows the void ratio in surface in Section A-1 and Section B were relatively smaller than those of other sections, but the void ratio in binder course in Section B were larger than those of other sections. Therefore, the mechanism of damage in Section B may be different with other sections, because of different structure in pavement. 
It was concluded that crack patterns in porous asphalt with cubic stone and binder which satisfied with Kyoto Specifications did not almost change from initial condition and it connected to the long life in porous asphalt.

\section{Water content of mixture in plant and local rutting in the field}

\subsection{Water content in hot mixture in plant (Batch type)}

Water content of aggregate, which affected to stripping of aggregate and rut depth, was described before 4.2.1. Then, in advance for construction in Kyoto Jukan Expressway, water content in hot mixtures, which were manufactured by conventional method and method, had been examined as follows. The type of asphalt plant is used in batch type in Japan.

Cold aggregate (5 - $13 \mathrm{~mm}$ : andesite, water absorption: $1.85 \%$ ) was taken from on the feeder of aggregate just before charge to dryer and heated aggregate in hot bin was taken from the sample, considering with the time difference in feeder of cold aggregate. The temperature after discharging in hot mixture was measured at every two batches in the top of the pile of hot mixture on dump truck. The temperature of the field in hot mixture was measured at initial mixture and final mixture of charge (two times/dump 
truck) on the dump truck just before asphalt finisher from dump truck. Water content in hot mixture $(200 \mathrm{~g})$ was measured by radiation of microwave $500 \mathrm{~W}$ for ten minutes.

Water content and temperature in hot mixture were already measured, but the relationships between water content and shipment temperature of hot mixture was not yet clarified. Fig. 7 and Fig. 8 show the variation of water content in aggregate and mixture for asphalt treated base course which were manufactured by conventional methods and the variation of water content in aggregate in both hot bins were similar with each other, but larger size of aggregate in hot bin three (andesite, water absorption: $1.85 \%, 5-13 \mathrm{~mm})$ was remarkably larger than that in aggregate in hot bin one $(2.5 \mathrm{~mm}$ under) and it affected to water content of porous mixture.

Fig. 9 shows the water content in hot mixture at conventional asphalt plant and field and shipment temperature for porous asphalt. Maximum water content of aggregate (batch: 29) in porous asphalt corresponded to lowest shipment temperature.

Fig. 10 shows the water content in hot mixture for porous asphalt in Kyoto Jukan Expressway and it was sufficiently controlled according to specification $(<0.1 \%)$ of Kyoto Jukan Expressway.

Therefore, it seems that control of water content in aggregate for porous asphalt is important for temperature control of mixture. 
It is clear that water content in cold aggregate affected to the shipment temperature in hot mixture. They show the conventional temperature control system in mixing dryer was inadequacy in temperature control to prevent the local cooling in porous asphalt, comparing with results according to Kyoto Specification.

It was concluded that water content may cause to local cooling of hot mixture in the field.

\subsection{Local rutting in the field}

In general, it was believed that the life of porous asphalt was relatively shorter, comparing with that of dense type mixture. Then, wheel tracking test of TRRL type (contact pressure: $0.54 \mathrm{MPa}$ ) for both type mixtures was performed to examine the strain around aggregate. It was confirmed that the strain (max: 5,810,000 x 10 $0^{-6}$ ) around aggregate in porous asphalt (void content: $19.9 \%$, binder content: $5.0 \%$ ) was larger than that (max: $2,150,000 \times 10^{-6}$ ) of dense type mixture (void content: $3.8 \%$, binder content: $6.0 \%$ ) under wheel tracking test of TRRL type at $45^{\circ} \mathrm{C}$ for one hour, through the maximum rut depth $(1 \mathrm{~mm})$ in porous asphalt was smaller than maximum rut depth (6 $\mathrm{mm})$ in dense type mixture for one hour [7]. Therefore, it was supposed the life in 
porous asphalt become shorter by large strain, though rut depth of porous asphalt was always smaller than that of dense type mixture.

Then, the experiment for local rutting in the field using dense type mixture, in which larger rut depth occurred, was performed to examine the relationships of local temperature and local rutting in Osaka in Japan, because both mixtures show the same visco-elastic behavior like rutting. It was performed at the pavement on concrete bridge at autumn (ambient temperature: $7^{\circ} \mathrm{C}$ ). The surface course (thickness: $4 \mathrm{~cm}$ ) was cut and paved in the field using gap type coarse mixture (Table 4) and the modified binder was used in surface course. Surface temperature measure by infrared camera was rearranged with $2^{\circ} \mathrm{C}$. The traffic volume in this section was 10,000 vehicles/day/lane and heavy trucks were observed in this section.

The temperature distribution $\left(0.1^{\circ} \mathrm{C}\right)$ on the surface of pavement at one hour later after finished was measured at gondola of $5 \mathrm{~m}$ high using infrared camera (Fig. 11). Two years later, the local rutting (relative rutting: $0.1 \mathrm{~mm}$ ) at range of $3.5 \times 3.3 \mathrm{~m}$ (traffic lane) was measured by $3 \mathrm{~m}$ profile meter by $10 \mathrm{~cm}$ in length and width using standard height in both white lines (inner white line and outer white line)(Fig. 12).

Void distribution in depth in mixture depends upon the surface temperature and bottom temperature after finishing, but void in depth gradually decrease with time 
(densification of mixture and/or rutting) under moving wheel at high temperature. Then, it is important to examine the relationship between temperature after finishing and rut depth, because void ratio in upper part in mixture is larger than that of bottom and the densification of mixture (local rutting) in local cooling points (local cooling) occurred with time.

Fig. 11 and Fig. 12 show the temperature distribution and degree of local rutting. It was clear that both distributions were similar with each other. Red arrows were expressed with the main path of truck and passenger car and black arrow was expressed the direction of moving vehicles. Outer white line in Fig. 11 and Fig. 12 show the bands between S32 and S33.

In this section, pothole phenomenon was also observed at low temperature point (point: S5, K126) in Fig. 11 after one month and it was repaired, but measurement of local rutting was performed after repaired, because of small area. It was supposed that the cause of pothole was caused by large strain due to moving load in local cooling spot.

Fig. 13 shows the relation between local temperature and local unevenness in this section at every $10 \mathrm{~cm}$ square. Red arrows in Fig. 13 may show the main path of truck and passenger car. Maximum correlation coefficient between local rutting and local 
temperature was observed near outer wheel path (point 28 in Fig. 13, Fig. 11, and Fig.

12) and it was caused by main path of both vehicles.

While, maximum temperature difference on pavement surface after finished was $40^{\circ} \mathrm{C}$ or more [29], even if porous asphalt were constructed in hot summer, and the life (design life: 10 years) in porous asphalt (void ratio: $15 \%$ ) in Japan was 3 - 4 years in average and even if the shipping temperature in hot mixture was strictly controlled in asphalt plant, according to Kyoto specifications, temperature difference on pavement surface after finished reached to $8.1^{\circ} \mathrm{C}$ in average.

It was concluded that relative low temperature on pavement surface due to local cooling was related to the local rutting and pothole, and temperature control on the pavement surface just finished (It was the last check method to evaluate the quality of mixture) was important to hold the long life in asphalt pavement, even if the temperature in hot mixture was controlled by Kyoto Specifications. If the temperature difference on the pavement surface after finished were larger than $15^{\circ} \mathrm{C}$ or larger, it was specified to refuse the acceptance in porous asphalt in Kyoto Jukan Expressway. When pothole and crack occurred in porous asphalt for two or three years, it was obliged to repair the constructor in free charge by administrator in Kyoto Jukan Expressway. 


\section{Conclusions}

The following conclusions were obtained in this study.

1) When the porous asphalt was constructed in accordance with innovative Kyoto Specifications, regarding binder properties, manufacturing method of mixture, asphalt plant, construction methods, water content of mixture, type of crushed stone (cubic stone) and construction machine, the porous asphalt with homogeneous mixture was obtained and it may be related with the long life in porous asphalt.

2) Even if porous asphalt was manufactured by Kyoto Specifications, the difference of temperature on porous asphalt after finished reached to $8.1^{\circ} \mathrm{C}$ in average, but it was remarkably lower than that of conventional construction in Japan.

3) The crack properties due to movement of aggregate in porous asphalt depend upon the shape of aggregate, properties of binder and pavement structure.

4) Even if the cracks or rut depth in surface in porous asphalt was not observed, fatigue in binder course or asphalt treated base course occurred. 
5) The low temperature zone after finishing connected to pothole by large strain due to movement of aggregate under moving load in dense type mixture.

6) The diagnosis (degree of damage) in pavement structure can be conducted by CT scanner and three dimensional crack analyses.

\section{Acknowledgment}

Upon carrying out those researches, there were overall supports of Kyoto Prefectural Road Public Corporation and technical supports from both NIPPO Corporation and Obayashi Road Corporation. The authors would like to express their gratitude here again to these parties. 


\section{References}

[1] National Cooperative Highway Research Program (NCHRP) Report 468, Contributions of Pavement Structural Layers to Rutting of Hot Mix Asphalt Pavements, Transportation Research Board, National Research Council, National Academy Press, Washington D.C.2002;

[2] Prithvi S. Kandhal and L. Allen Cooley, Jr., Evaluation of permanent deformation of asphalt mixtures using loaded wheel tester, NCAT Report. 2002; No.2002-08.

[3] Hannele K. Kanerva, Ted S. Vinson and Huayang Zeng, Low-temperature cracking: Field validation of the thermal stress restrained specimen test, Strategic Highway Research Program, National Research Council, 1994; SHRP-A-401.

[4] D. Jones, J. Harvey, and C. Monismith, Reflective cracking study: Summary Report, California Department of Transportation, UCPRC-SR-2007-01, 2007; $1-79$.

[5] Jim ST. Martin, John T. Harvey, Fenella Long, Eul-Bum Lee, Carl L. Monismith and Kevin Herritt, Long-life rehabilitation design and construction, Perpetual bituminous pavements, Transportation Research Circular, 2001; No. 503, 51-65.

[6] Santucci, L.E., Minimizing moisture damage in asphalt pavements, Pavement Technology Update, The University of California Pavement Research Center, 
Technology Transfer Program, 1985; 2(2), 1-12.

[7] Takashi Kondo, Akihiro Moriyoshi, Takaki Yoshida, Souichi Takahashi, Crack formation in asphalt mixtures in the wheel tracking test at high temperature, Journal of the Japan Petroleum Institute, 2004; 47, (2) 90-99.

[8] Takashi Kondo, Akihiro Moriyoshi, Takaki Yoshida, Souichi Takahashi, Movement characteristics of aggregate in asphalt mixtures during the wheel tracking test, Journal of the Japan Petroleum Institute, 2003; 46,(3) 172-180.

[9] Akihiro Moriyoshi, Naoyuki Takahashi, Osamu Ikeda, Masato Kawashima, Takahiko Akabane, Strain distribution in asphalt mixtures during the wheel tracking test at high temperatures, Construction and Building Materials, Vol.40, issue 1, January, 2013; 1128-1135.

[10] Akihiro Moriyoshi, Takashi Tomoto, CT scan analyses for surface course of porous pavement after 8 years at Kyoto highway, 5as Jornadas Internacionales Delasfalto, 2006; September.

[11] Manual for investigation and test methods in pavement, Japan Road Association, Volume 4, 2007.

[12] T. Tomoto, A. Moriyoshi, Evaluation of Damage to Asphalt Pavement using a Micro-focus CT Scanner and Three-dimensional Crack Analyses, Road Materials 
and Pavement Design, 10(3), July-September, 2009; 519-544.

[13] Timothy Schmidt and John Tyson, Full-field dynamic displacement and strain measurement using advanced 3D image correlation photogrammetry, Experimental Techniques, Part I :May/June, 27,(3): 47-50, Part II : July/Aug.27, 2003; (4): 44-47.

[14] H. Ishikawa, S. Takahashi, T. Nakai and A. Moriyoshi, Innovation in porous pavement quality control for cold regions on the AYABE-MIYAZU Road in Japan, Proc. of the 3rd European Symposium on performance and durability of bituminous materials and hydraulic stabilized composites, 1999; 653-662.

[15] Akihiro Moriyoshi, Toshiro Jin, Takaaki Nakai, Hiroshi Ishikawa, Evaluation methods for porous asphalt pavement in service for fourteen years, Construction and Building Materials, Vol.42, May, 2013; 190-195.

[16] Hiroshi Ishikawa, Tsutomu Gento, Hiroshi Hasegawa, Shin-ei Takano, and Akihiro Moriyoshi, Evaluation method for aging asphalt after Thin Film Oven Test, Journal of the Japan Petroleum Institute, 2001; 44(2), 120-124 (in Japanese, Summary in English).

[17] A. Moriyoshi and H. Ishikawa, Effects on fracture strain of bitumen on low temperature cracking, Eurobitume Workshop'99 on Performance related 
properties for bituminous binders, 1999; No139,1 - 4.

[18] Mallick, Rajib B, Tao, Mingjiang, Chen, Bao-Liang, O’Sullivan, Karen, and Cacciatore, Peter, Practical method to understand the effect of aggregate drying on the moisture content of hot-Mix asphalt, Transportation Research Record, Journal of the Transportation Research Board, Issue 2011; No. 2208, 11-3346, 90-96.

[19] Bennert, Thomas, Maher, Ali, and Sauber, Robert, Influence of production temperature and aggregate moisture content on the initial performance of warm-Mix asphalt, Transportation Research Record, Journal of the Transportation Research Board, 2011; Issue No. 2208, 97-107.

[20] Vaughan Voller, Tom McGannnon, Dave Rindal, David Timm, Timothy R. Clyne, and David Newcomb, Measurement of moisture in aggregate stockpiles, Final Report, Minnesota Department of Transportation, 39. MN/RC- 2001-21, Minnesota Department of Transportation, 39, 2001.

[21] Department of Transportation Engineering Service Center, Method of determining moisture content of asphalt mixtures or mineral aggregate using microwave ovens, California Test 370, January. 2000.

[22] Akihiro Moriyoshi and Eiichi Gotho, Low temperature properties of asphalts for 
pavements, Journal of the Japan Petroleum Institute, 1992; 44(2), 208-211. (in Japanese, Summary in English)

[23] K. Tokumitsu, A. Moriyoshi, K. Kawamura, and A. Kasahara, Temperature and void ratio of asphaltic layers constructed in cold and ordinary seasons, Journal of the Japan Petroleum Institute, 1995; 38(3), 173-184.

[24] A. Kasahara, T. Amano, K. Tokumitsu, and A. Moriyoshi, Effects of rolling conditions on void ratio and strength of asphaltic mixture, Journal of the Japan Petroleum Institute, 1997; 40(1), 39-45.

[25] Asphalt Compaction, Australian Asphalt Pavement Association, 2010; 1-14.

[26] Frazier Parker, Residual moisture in hot mix asphalt concrete, Auburn University Highway Research Center. 1996;

[27] Moisture sensitivity of asphalt pavements, A national seminar, Transportation Research Board, 2003; 1-345.

[28] Japan Road Association. Manual for test method of pavement; 2010; [PartIII, [3]-039]

[29] A. Moriyoshi, Suggestion to long life pavement, Doboku Gakkaishi, 2004; 89(6), 43-45. (in Japanese) 
Table 1. Properties and specifications of porous asphalt in Kyoto Jukan Expressway and Japan

\begin{tabular}{|c|c|c|c|c|}
\hline & $\begin{array}{l}\text { Binder } \\
\text { Type A }\end{array}$ & $\begin{array}{l}\text { Binder } \\
\text { Type B }\end{array}$ & $\begin{array}{l}\text { Specification } \\
\text { of Japan* }\end{array}$ & $\begin{array}{l}\text { Specification of } \\
\text { Kyoto Highway }\end{array}$ \\
\hline $\begin{array}{l}\text { Penetration }\left(25^{\circ} \mathrm{C}, 100 \mathrm{gr}, 5 \mathrm{sec}\right) \\
(1 / 10 \mathrm{~mm})\end{array}$ & 41 & 79 & $>41$ & $>40$ \\
\hline Softening Point $\left({ }^{\circ} \mathrm{C}\right)$ & 98.0 & 101.0 & $>80.0$ & $>80.0$ \\
\hline Ductility $\left(15^{\circ} \mathrm{C}\right)(\mathrm{cm})$ & $100+$ & $100+$ & $>50$ & $>50$ \\
\hline Flashing Point $\left({ }^{\circ} \mathrm{C}\right)$ & 325 & 310 & $>260$ & $>260$ \\
\hline Toughness $\left(25^{\circ} \mathrm{C}\right)(\mathrm{Nm})$ & 26.0 & 26.5 & $>20$ & $>20$ \\
\hline Tenacity $\left(25^{\circ} \mathrm{C}\right)(\mathrm{Nm})$ & 21.4 & 25.0 & $>15$ & $>15$ \\
\hline Viscosity at $60{ }^{\circ} \mathrm{C}(\mathrm{kPa} \cdot \mathrm{s})$ & $100+$ & $100+$ & $>20$ & $>20$ \\
\hline Weight Loss after TFOT (\%) & +0.06 & +0.04 & $<0.6$ & $<0.6$ \\
\hline $\begin{array}{l}\text { Degree of Penetration } \\
\text { After TFOT }\end{array}$ & 85.4 & 76.0 & $>65$ & $>65$ \\
\hline FBP after $\mathrm{TFOT}\left({ }^{\circ} \mathrm{C}\right)$ & -25 & -20 & - & $<\mathrm{T}_{\mathrm{AV}}{ }^{++}(-4)$ \\
\hline MBP after $\mathrm{TFOT}\left({ }^{\circ} \mathrm{C}\right)$ & -27 & -38 & - & $<\mathrm{T}_{\mathrm{L} .}^{+++}(-10)$ \\
\hline MBP before TFOT $\left({ }^{\circ} \mathrm{C}\right)$ & -28 & $<-40$ & & \\
\hline Strength at $(\mathrm{FBP})^{\circ} \mathrm{C},(\mathrm{MPa})$ & 7.4 & 5.2 & - & $>5$ \\
\hline Strength at $(\mathrm{FBP}-10)^{\circ} \mathrm{C},(\mathrm{MPa})$ & 8.5 & 8.0 & - & $>5$ \\
\hline $\begin{array}{l}\text { Fracture strain at }(\mathrm{FBP}-10)^{\circ} \mathrm{C} \text {, } \\
\left(\mathrm{x} 10^{-2}\right)\end{array}$ & 0.68 & 0.80 & - & $>0.3$ \\
\hline $\operatorname{HTLTD}\left(163^{\circ} \mathrm{C}, 72 \mathrm{hrs}\right),\left({ }^{\circ} \mathrm{C}\right)$ & -11 & -16 & - & $<-10$ \\
\hline Wax & None & None & - & Not be included \\
\hline
\end{tabular}

Table 2. Main properties in four sections of Kyoto Jukan Expressway

\begin{tabular}{lcccc}
\hline Layer & Thickness & Binder type & Binder content & Air void \\
\hline & $(\mathrm{cm})$ & & $(\%)$ & $(\%)$ \\
\hline $\begin{array}{l}\text { Surface(Porous asphalt) } \\
\begin{array}{l}\text { Binder course (Binder) } \\
\text { (Coarse type mixture) }\end{array}\end{array}$ & 6 & SBS modified & 5 & 20 \\
$\begin{array}{l}\text { Asphalt treated base } \\
\text { (Base) }\end{array}$ & 7 & Straight 80/100 & 5.5 & \\
Crushed stone base & 17 & Straight 80/100 & 5.5 & \\
\hline
\end{tabular}


Table 3. Characteristics of aggregate for porous asphalt in Kyoto and Japan

\begin{tabular}{lccc}
\hline & $\begin{array}{c}\text { Coarse Aggregate } \\
\text { Kyoto }\end{array}$ & $\begin{array}{c}\text { Specification } \\
\text { in Japan* }\end{array}$ & $\begin{array}{c}\text { Specification } \\
\text { of Kyoto Highway }\end{array}$ \\
\hline Specific Gravity & 2.74 & $>2.45$ & $>2.50$ \\
Water Absorption (\%) & 0.45 & $<3.0$ & $<3.0$ \\
Abrasion Loss (\%) & 9.9 & $<30$ & $<30$ \\
Soundness in Na $\mathrm{SO}_{4}(\%)$ & 1.6 & $<12$ & $<12$ \\
Soft Pieces (\%) & 2.0 & $<5.0$ & $<5.0$ \\
Flat or Elongated Particles (\%) & 9.8 & $<10$ & \multicolumn{2}{c}{ Inspection by } \\
Durability & pass & - & \multicolumn{2}{c}{ X-ray analyses*** } \\
Clay, Clay Agglomerates (\%) & \multicolumn{2}{c}{$<0.25$} & $<0.25$ \\
\hline
\end{tabular}

*: Specification in Japan, Manual for Design and Construction of Asphalt Pavement

**: Particles having a ratio of 3 or more between the largest and the smallest dimensions (A ratio of 5 or more for Specification in Japan)

***: X-ray Analyses: Aggregate does not include smectite (20:5.9), corrensite (20:14.3) by X-ray analyses, after aggregate was immersed in various type of solution $\left(\mathrm{CaCl}_{2}, \mathrm{NaCl}, \mathrm{CMA}\right.$, Urea and anion type surfactant $)$ of $0.5 \%$ for one week.

Table 4. Compositions, binder content, maximum rut depth, void ratio, dynamic stability

\begin{tabular}{ccccc}
\hline $\begin{array}{l}\text { Sieve } \\
\begin{array}{l}\text { Opening } \\
(\mathrm{mm})\end{array}\end{array}$ & $\begin{array}{l}\text { Gap type } \\
\text { coarse } \\
\text { (Surface) }\end{array}$ & $\begin{array}{l}\text { Porous } \\
\text { asphalt } \\
\text { type } \\
\text { Kyoto) }\end{array}$ & $\begin{array}{c}\text { Porous } \\
\text { asphalt } \\
\text { type }\end{array}$ & $\begin{array}{c}\text { Asphalt } \\
\text { treated } \\
\text { base } \\
\text { course }\end{array}$ \\
\hline Binder type & $\begin{array}{l}\text { Modified } \\
\text { binder }\end{array}$ & $\begin{array}{l}\text { Kyoto } \\
\text { Spec. }\end{array}$ & $\begin{array}{c}\text { Modified } \\
\text { binder }\end{array}$ & $\begin{array}{c}\text { Straight } \\
\text { asphalt }\end{array}$ \\
\hline $\begin{array}{l}\text { Mixture } \\
\text { Type }\end{array}$ & Type C & Type A & Type B & Type D \\
\hline 53.0 & - & & - & - \\
37.5 & - & & - & 100 \\
26.5 & - & & & 88.5 \\
19.0 & 100 & 100 & 100 & 78.0 \\
13.2 & 99.0 & & & 68.4 \\
9.5 & & 18.1 & 28.9 & 44.7 \\
4.75 & 55.0 & 17.2 & 22.7 & 34.0 \\
2.36 & 44.1 & 14.5 & 16.0 & 22.4 \\
0.6 & 28.1 & 9.0 & 10.1 & 15.6 \\
0.3 & 16.0 & & &
\end{tabular}




\begin{tabular}{lrccc}
\multicolumn{1}{c}{0.15} & 10.3 & 5.4 & 6.5 & 8.5 \\
\multicolumn{1}{c}{0.075} & 7.2 & 4.5 & 4.9 & 5.7 \\
\hline $\begin{array}{l}\text { Additive of } \\
\text { Abocel }\end{array}$ & \multicolumn{3}{c}{$\begin{array}{c}\text { Abocel }(1 \mathrm{~kg}) / \\
\text { Mixture (1 ton) }\end{array}$} \\
\hline $\begin{array}{l}\text { Binder } \\
\text { Content (\%) }\end{array}$ & 5.5 & 5.0 & 5.6 & 4.5 \\
\hline $\begin{array}{l}\text { Dynamic } \\
\text { stability* } \\
\text { (pass } / \mathrm{mm}, 1 \mathrm{~h}\end{array}$ & 8,100 & \\
$\begin{array}{l}\left(60^{\circ} \mathrm{C}\right) \\
\text { Void ratio }(\%)\end{array}$ & & \\
\hline $\begin{array}{l}\text { Cantabro loss } \\
(\%)\left(-20^{\circ} \mathrm{C}\right)\end{array}$ & 20.0 & 17.0 \\
\hline
\end{tabular}

\#: Numbers in Table indicate \% passing the sieve

*: Inverse of rate of deformation ( $\mathrm{mm} /$ minutes) between 45 minutes and 60 minutes (pass $/ \mathrm{mm}$ )

Table 5. Porous mixture in Kyoto Jukan Expressway

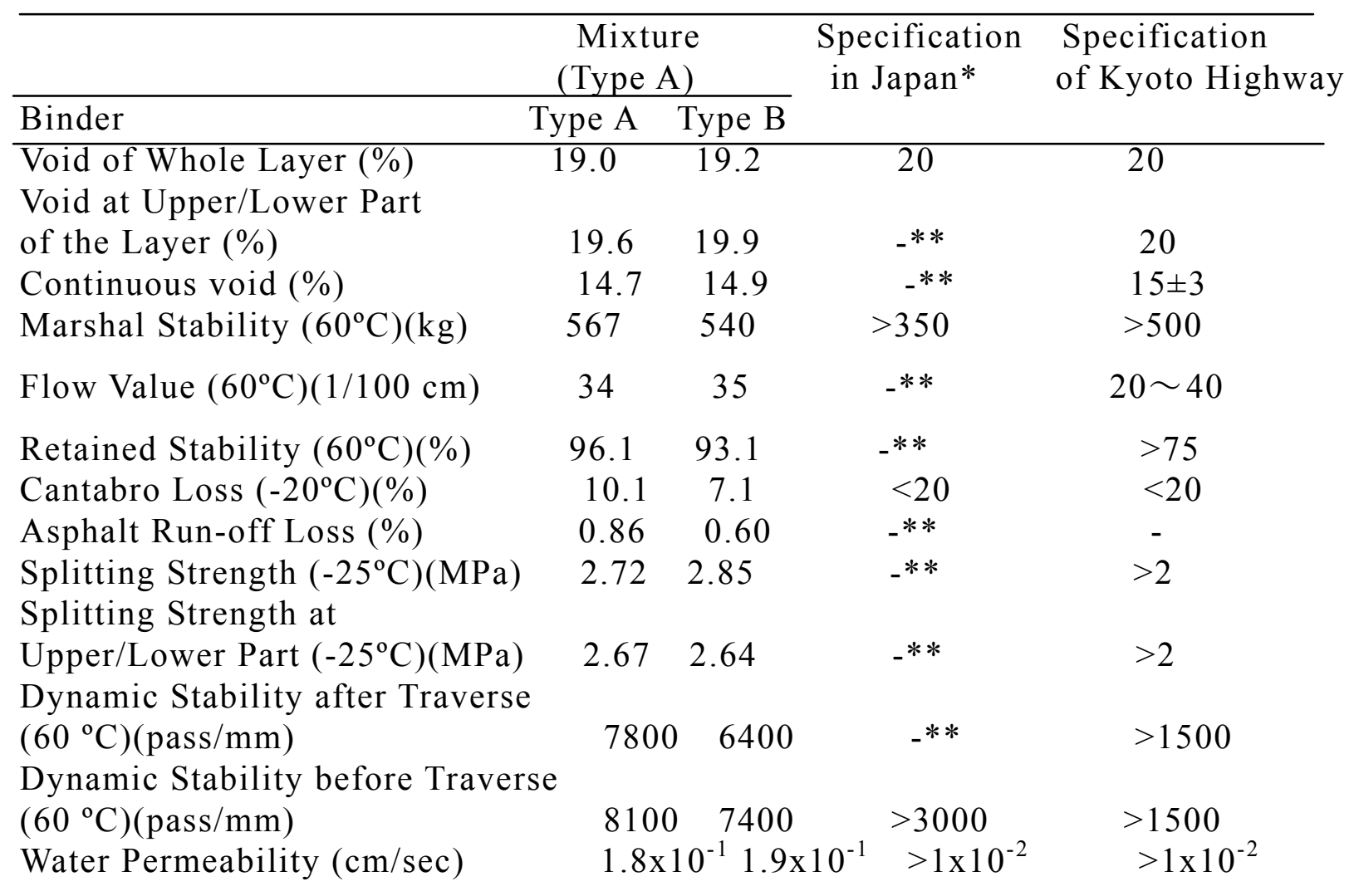


Water content (\%)

0.025

$<0.1$

*: Specification in Japan, Technical Guide for Porous Pavement (proposal)

$* *$ : It is not specified.

Table 6. Variation for temperature and water content in binder, aggregate and mixture in Kyoto Jukan Expressway

\begin{tabular}{|c|c|c|c|c|}
\hline & amples & Max. & Min. & Ave. \\
\hline $\begin{array}{l}\text { Heating temp. } \\
\text { of aggregate }\left({ }^{\circ} \mathrm{C}\right) \\
\left(\text { Criteria: } 185 \pm 10^{\circ} \mathrm{C}\right)\end{array}$ & 44 & 179 & 177 & 179 \\
\hline $\begin{array}{l}\text { Heating temp. } \\
\text { of binder }\left({ }^{\circ} \mathrm{C}\right) \\
\left(\text { Criteria: } 175 \pm 10^{\circ} \mathrm{C}\right)\end{array}$ & 44 & 173 & 171 & 171 \\
\hline $\begin{array}{l}\text { Temp. of hot mixture } \\
\text { (Criteria: } 175 \pm 7{ }^{\circ} \mathrm{C} \text { ) }\end{array}$ & 44 & 176 & 173 & 175 \\
\hline $\begin{array}{l}\text { Water contents in hot bin } \\
\text { one and three }(\%) \\
\text { (Criteria: }<0.1 \%)\end{array}$ & 36 & 0.06 & 0.02 & 0.04 \\
\hline $\begin{array}{l}\text { One Minute MBP test } \\
\text { (Criteria: original MBP } \\
\left.\left(-28^{\circ} \mathrm{C}\right)+1^{\circ} \mathrm{C}\right)(\text { Type A binder })\end{array}$ & 27 & \multicolumn{2}{|c|}{ lower than $-27^{\circ} \mathrm{C}$} & \\
\hline $\begin{array}{l}\text { One Minute MBP test } \\
\text { (Criteria: original MBP } \\
\left(-40^{\circ} \mathrm{C}\right) \text { (Type B binder) }\end{array}$ & 1 & \multicolumn{2}{|c|}{ lower than $-40^{\circ} \mathrm{C}$} & \\
\hline $\begin{array}{l}\text { Water contents immediately } \\
\text { after discharging hot mixture }(\%) \\
(\text { Criteria: }<0.1 \%)(\text { Type A binder })\end{array}$ & 11 & 0.05 & 0.01 & 0.025 \\
\hline $\begin{array}{l}\text { Water contents immediately } \\
\text { after discharging hot mixture }(\%) \\
(\text { Criteria: }<0.1 \%)(\text { Type B binder) }\end{array}$ & 5 & 0.04 & 0.01 & 0.022 \\
\hline
\end{tabular}


Table 7. Tests results after completed and under construction in Kyoto Jukan Expressway

\begin{tabular}{|c|c|c|c|c|}
\hline & Samples & Max. & Min. & Ave. \\
\hline $\begin{array}{l}\text { Water permeability test } \\
\text { on site }(\mathrm{sec}) \\
\text { (Criteria: }<10 \text { seconds of } \\
\text { outflow time of } 400 \mathrm{cc})\end{array}$ & 180 & 6.01 & 5.39 & 5.58 \\
\hline $\begin{array}{l}\text { Water permeability test } \\
\text { in laboratory }(\mathrm{cm} / \mathrm{sec}) \\
\left(\text { Criteria: }>10^{-2} \mathrm{~cm} / \mathrm{sec}\right)\end{array}$ & 180 & $4.0 \times 10^{-2}$ & $3.7 \times 10^{-2}$ & $3.9 \times 10^{-2}$ \\
\hline $\begin{array}{l}\text { Skid resistance }(\mathrm{BPN}) \\
(\text { Criteria: }>60)\end{array}$ & 33 & 65 & 61 & 62 \\
\hline $\begin{array}{l}\text { Shipment temperature } \\
\text { of hot mixture }\left({ }^{\circ} \mathrm{C}\right) \\
\left(\text { Criteria: } 175 \pm 7{ }^{\circ} \mathrm{C}\right)\end{array}$ & 343 & 182 & 174 & 178 \\
\hline $\begin{array}{l}\text { Spreading temperature } \\
\text { of asphalt mixture }\left({ }^{\circ} \mathrm{C}\right) \\
\left(\text { Criteria: } 165^{\circ} \mathrm{C}\right)\end{array}$ & 343 & 159 & 169 & 164 \\
\hline $\begin{array}{l}\text { Initial rolling temperature }\left({ }^{\circ} \mathrm{C}\right) \\
\left(\text { Criteria: } 155^{\circ} \mathrm{C}\right)\end{array}$ & 343 & 160 & 152 & 157 \\
\hline $\begin{array}{l}\text { Variation of temperature } \\
\text { immediately after spreading } \\
\text { by asphalt finishers }\left({ }^{\circ} \mathrm{C}\right) \\
\left(\text { Criteria: }<15^{\circ} \mathrm{C}\right)\end{array}$ & 90 & \multicolumn{3}{|c|}{$\begin{array}{c}\text { Ave. } 8.1^{\circ} \mathrm{C} \\
\text { (measured by infrared camera) }\end{array}$} \\
\hline
\end{tabular}




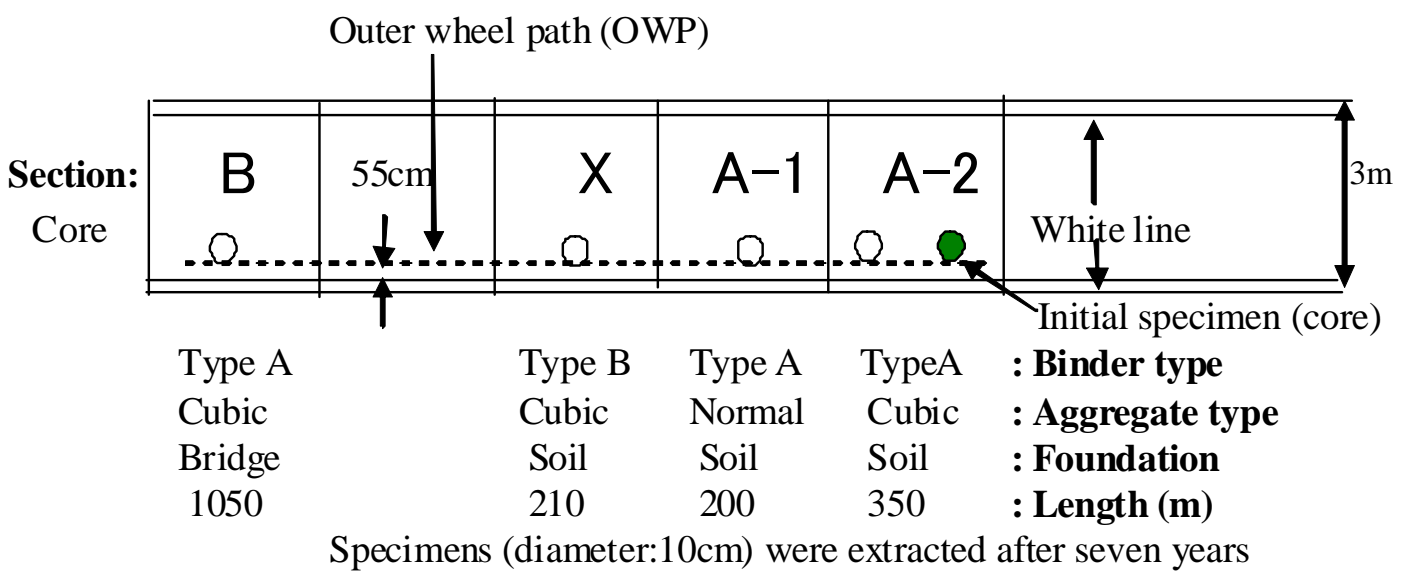

Fig. 1. Four test sections in Kyoto Jukan Expressway 

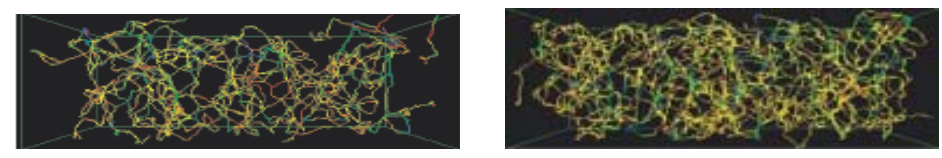

Surface, $1.2 \mathrm{~mm}, 20.2 \%$

Surface, $1.2 \mathrm{~mm}, 21.6 \%$
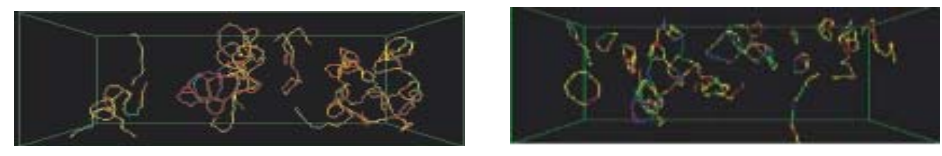

Binder(1),1.2mm,4.87 \% Binder(1),1.2mm,4.61\%
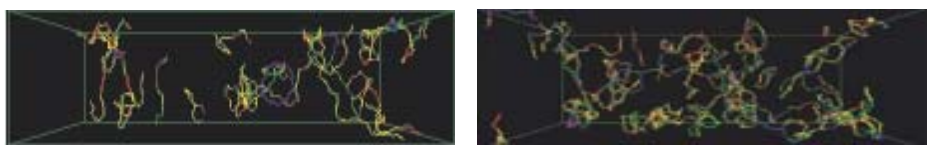

Binder(2),1.2mm,6.96 \% Binder(2),1.2mm,6.58 \%
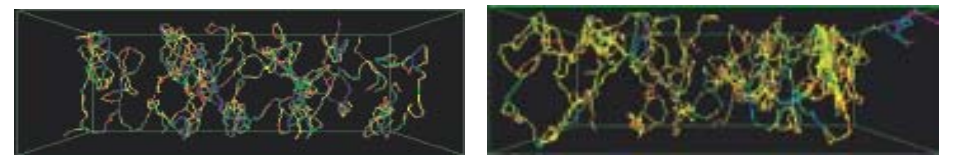

Base(1),1.2mm,7.78 \% Base(1),1.2mm,10.6\%
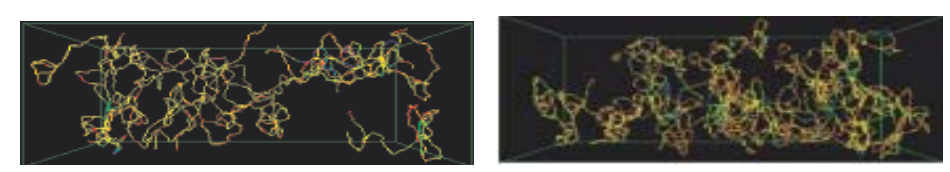

Base(2),1.2mm,8.92\% Base(2),1.2mm,9.87\%

Section A-2 (After 7 years), Section T (A-2, New)

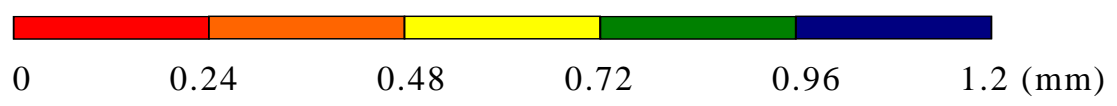

(Source: CBM, 2013, 42, Moriyoshi, A., [15])

Fig. 2. Crack distribution in Section $\mathrm{T}$ (Section A-2, new pavement) and Section A-2 after seven years 

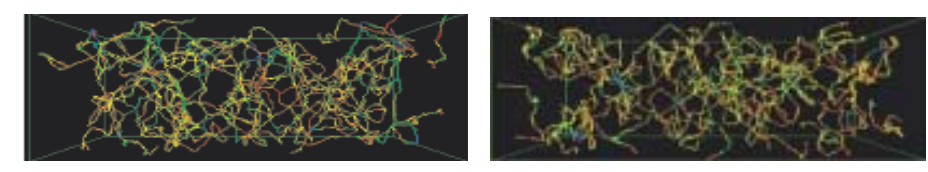

Surface,1.2mm,20.2 \% Surface, $1.2 \mathrm{~mm}, 14.7 \%$
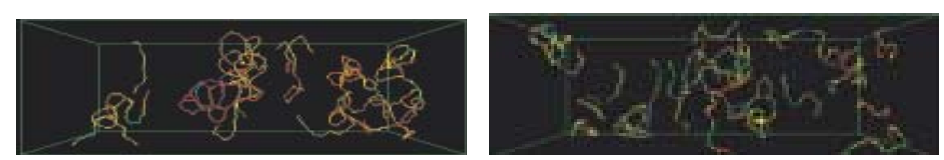

Binder(1),1.2mm,4.87 \% Binder(1),1.2mm,5.60\%
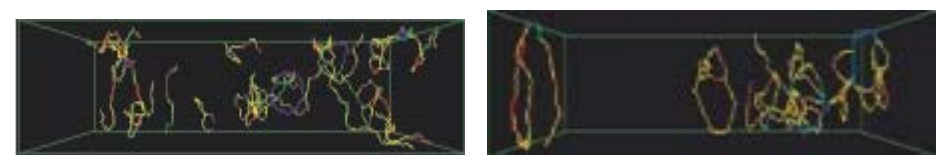

Binder(2),1.2mm,6.96 \% Binder(2),1.2mm,5.68 \%
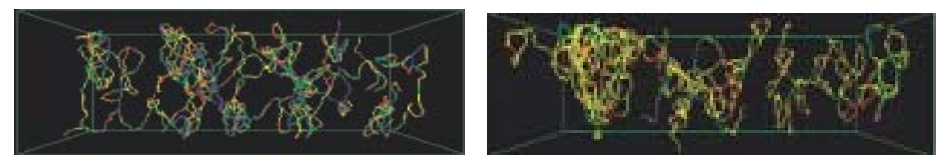

Base(1),1.2mm,7.78\%

Base(1),1.2mm,7.63\%
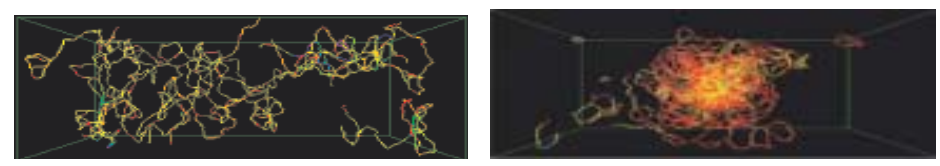

Base(2),1.2mm,8.92 \% Base(2),1.2mm,6.7\%

Section A-2

Section A-1

Treated stone by Barmac Untreated stone by Barmac

(Cubic stone) (Conventional stone)

$\begin{array}{llllll}0 & 0.24 & 0.48 & 0.72 & 0.96 & 1.2(\mathrm{~mm})\end{array}$

Fig. 3. Crack distribution in Section A-2 (Standard section, Barmac) and Section A-1 (conventional crushed rock) after seven years 

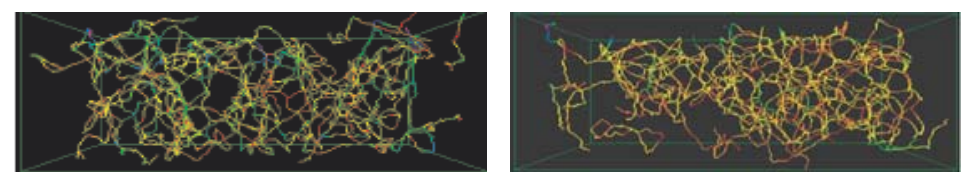

Surface, $1.2 \mathrm{~mm}, 20.0 \%$

Surface, $1.2 \mathrm{~mm}, 17.8 \%$
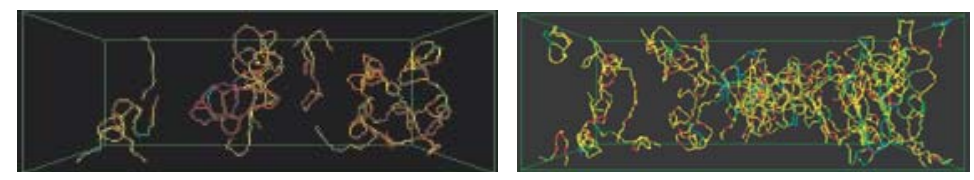

Binder(1),1.2mm,4.87 \% Binder(1),1.2mm,10.4\%
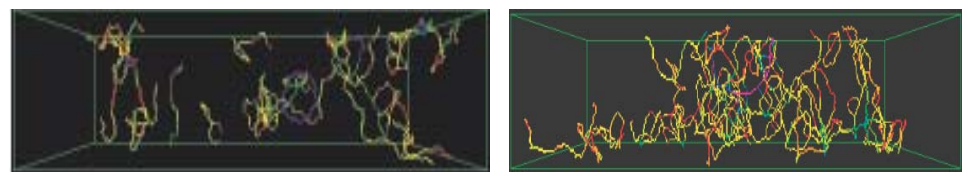

Binder $(2,1.2 \mathrm{~mm}, 6.96 \%$ Binder(2),1.2 mm,13.9\% Section A-2 Section B

(Standard section) (Pavement on concrete bridge)

$\begin{array}{llllll}0 & 0.24 & 0.48 & 0.72 & 0.96 & 1.2(\mathrm{~mm})\end{array}$

Fig. 4. Crack distribution in Section A-2 (Standard section) and Section B (Pavement on concrete bridge) after seven years 


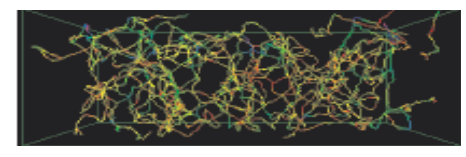

Surface,1.2mm,20.0\%

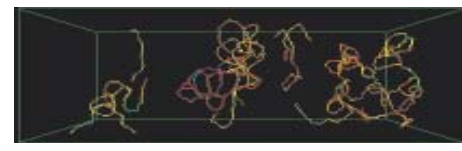

Binder(1),1.2mm,4.87 \%

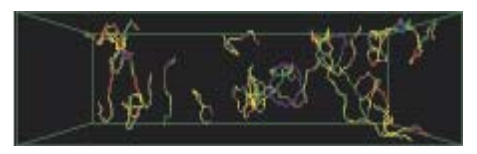

Binder(2),1.2mm,6.96\%

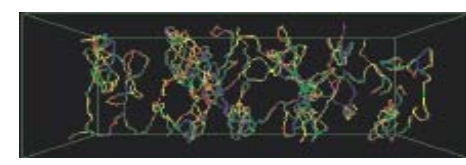

Base(1),1.2mm,7.78\%

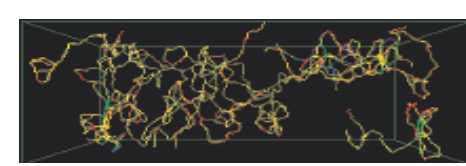

Base(2),1.2mm,8.92\%

Section A-2

(Binder Type A)

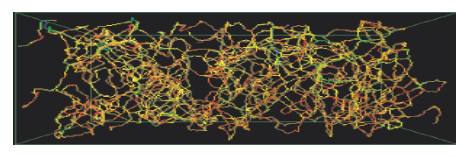

Surface,1.2mm,20.2\%

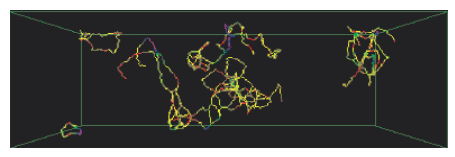

Binder(1),1.2mm,3.90\%

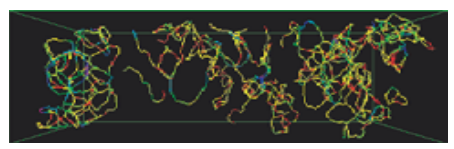

Binder(2), 1.2mm,8.82\%

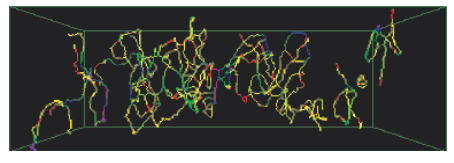

Base(1),1.2mm,6.96\%

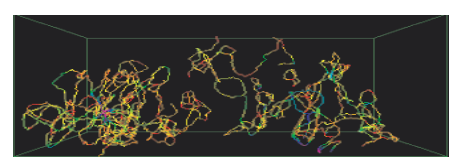

Base(2),1.2mm,10.2\%

Section $\mathrm{X}$

(Binder Type B)

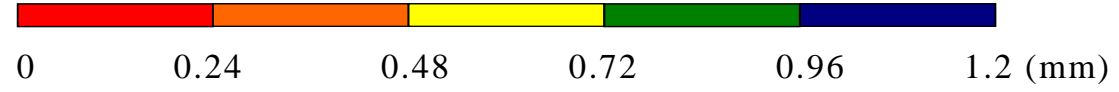

Fig. 5. Crack distribution in Section A-2 (Binder Type A) and Section X (Binder Type B) after seven years 


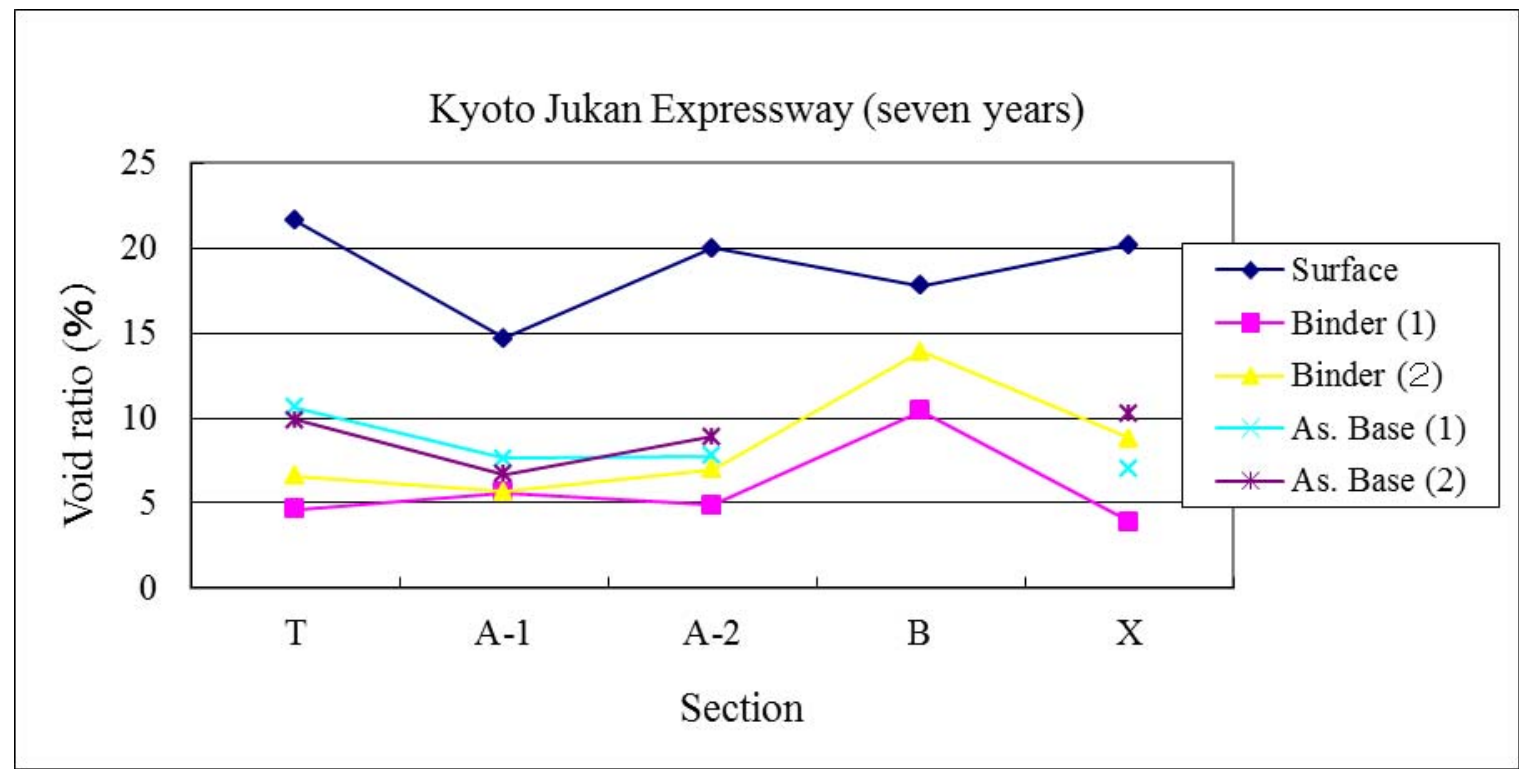

Fig. 6. The void ratio in each layer in four sections in Kyoto Jukan Expressway 


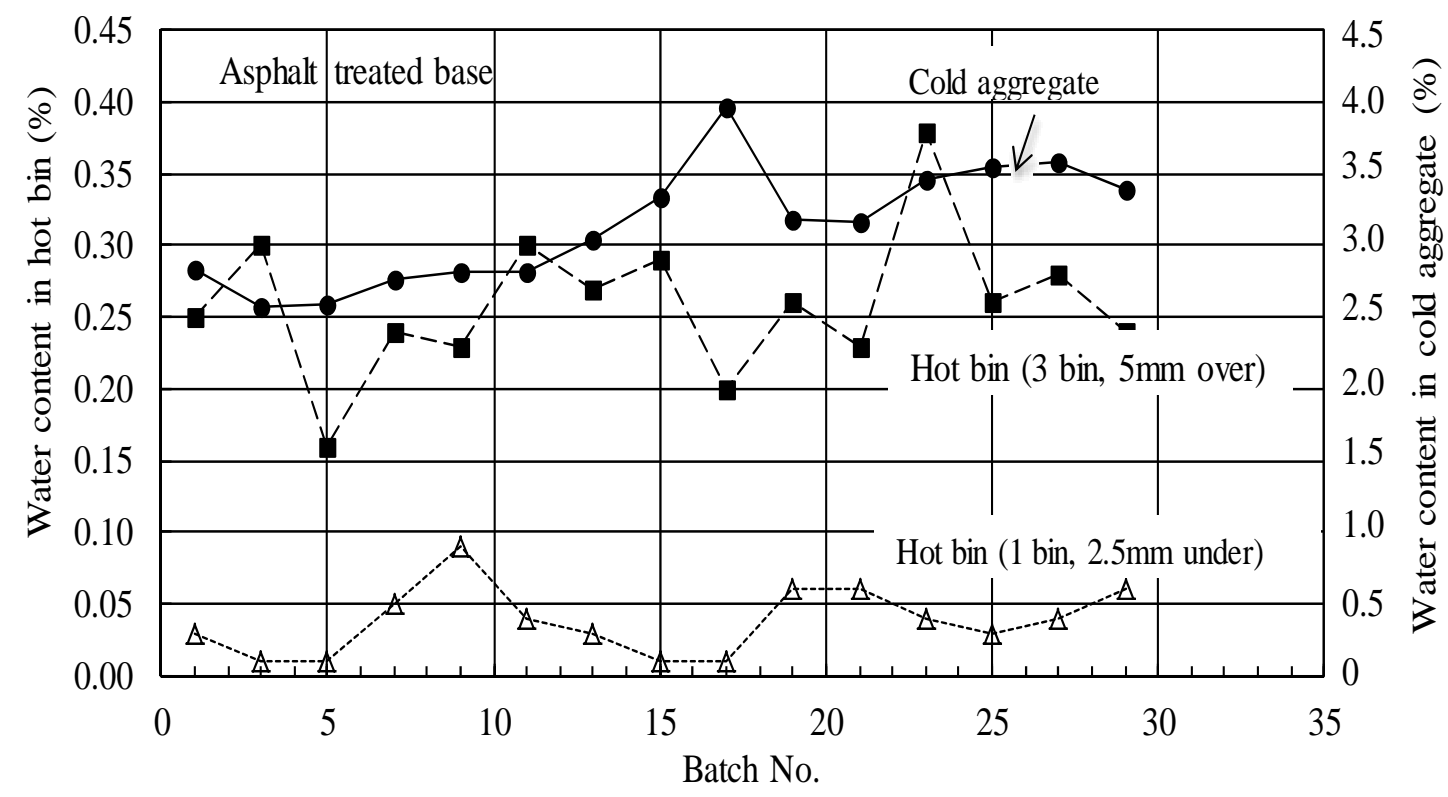

Fig. 7. Water content of aggregate in hot bin and water content of cold aggregate for asphalt treated base course 


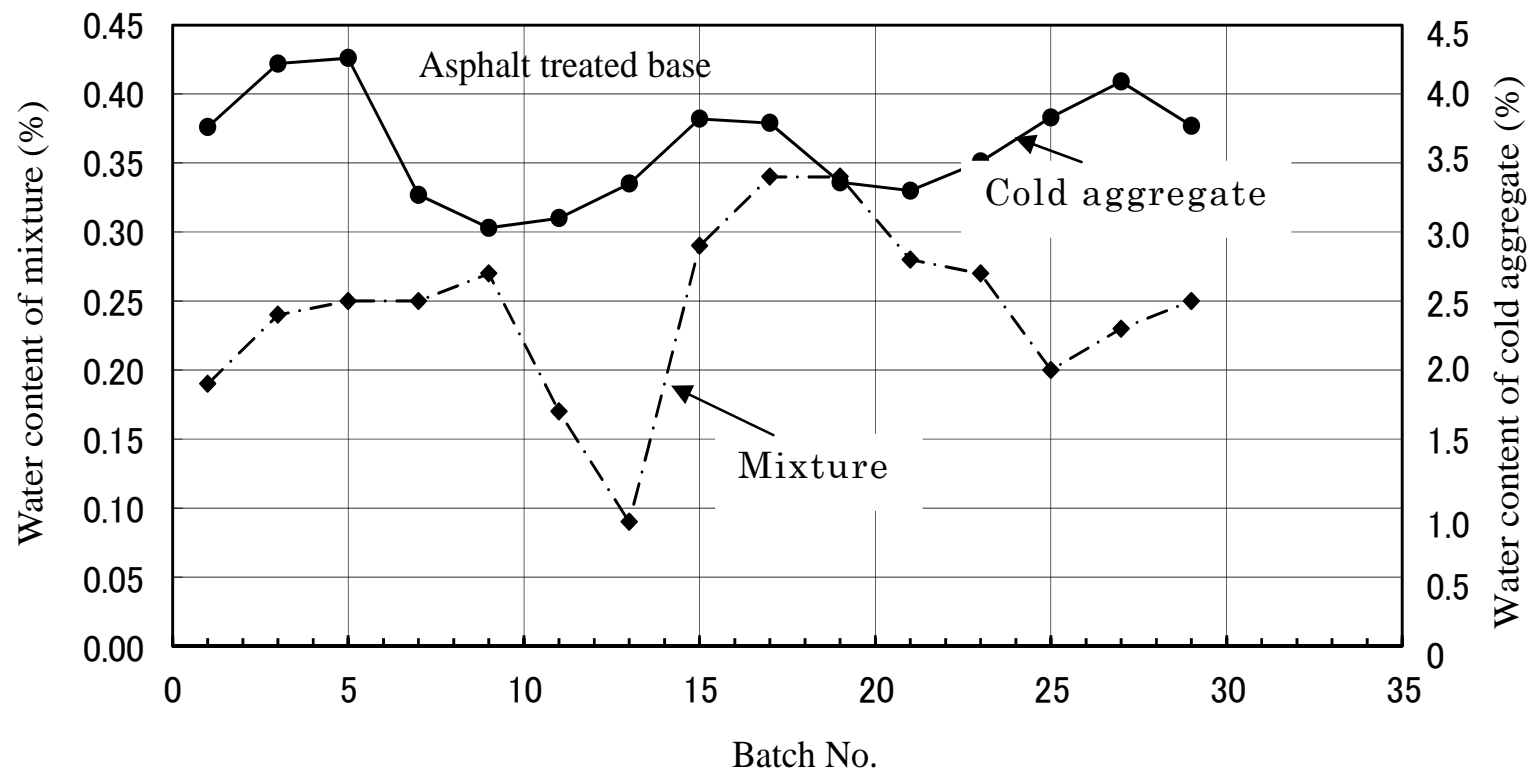

Fig. 8. Water content of mixture and water content of cold aggregate for asphalt treated base course 


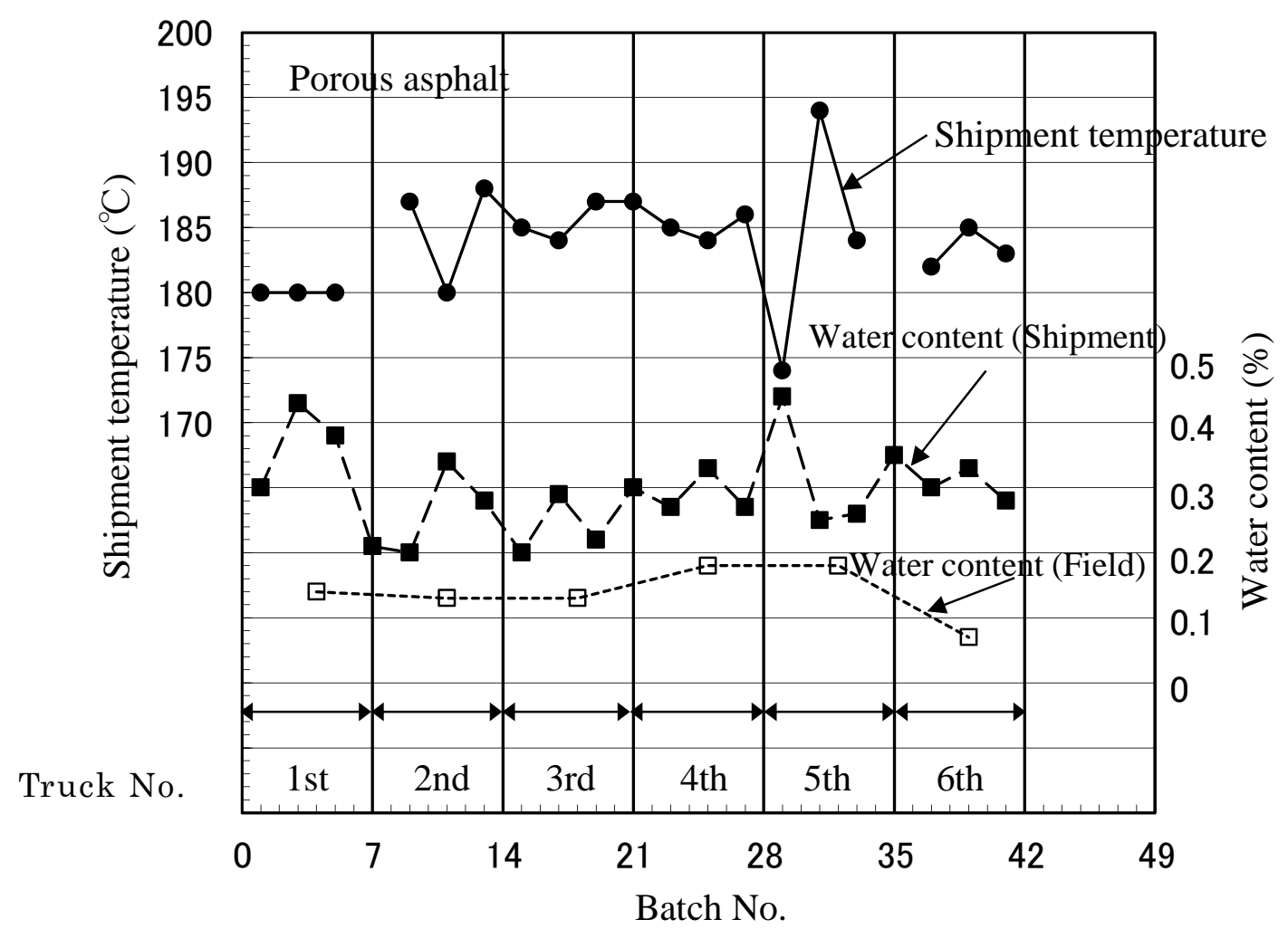

Fig. 9. Shipment temperature and water content of porous asphalt 


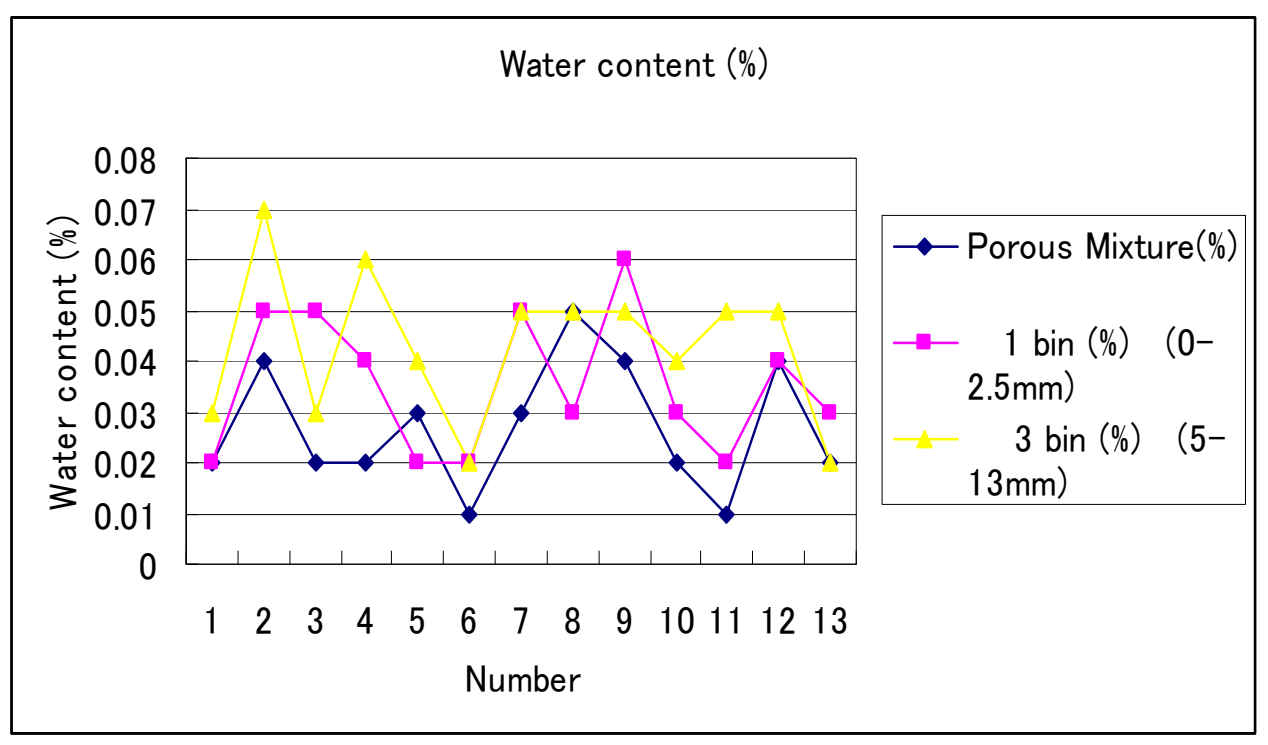

$\begin{array}{rl}\text { Number } & \text { Date } \\ 1 & 7 / 16 \\ 2 & 7 / 25 \\ 3 & 8 / 4 \\ 4 & 8 / 7 \\ 5 & 8 / 8 \\ 6 & 8 / 28 \\ 7 & 8 / 29 \\ 8 & 8 / 30 \\ 9 & 9 / 3 \\ 10 & 9 / 4 \\ 11 & 9 / 5 \\ 12 & 9 / 6 \\ 13 & 9 / 9\end{array}$

Fig. 10. Water content at shipment of mixture and at the hot bins in Kyoto-Jukan Expressway 


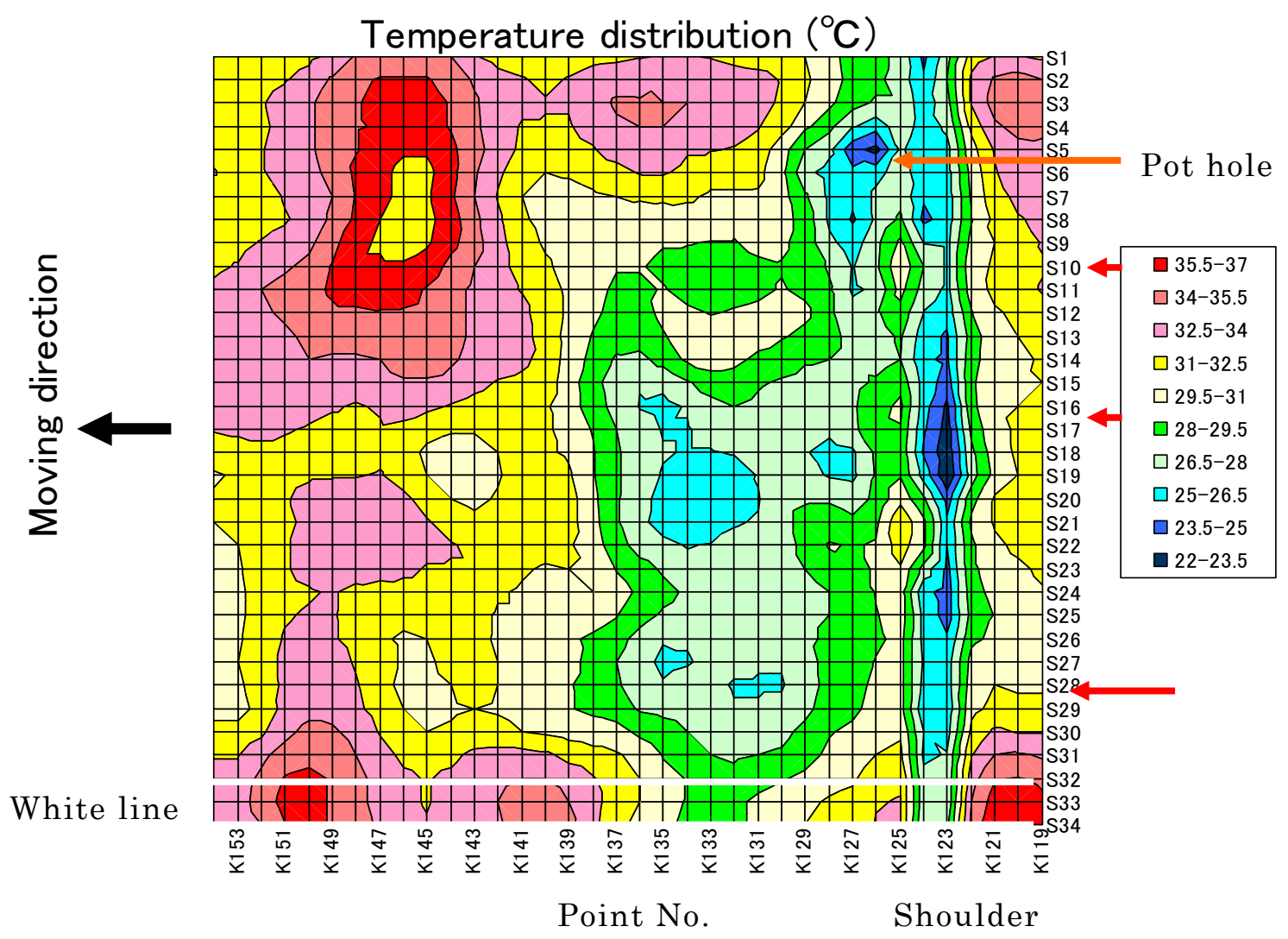

Fig. 11. Temperature distribution after just finishing (one hour later) 


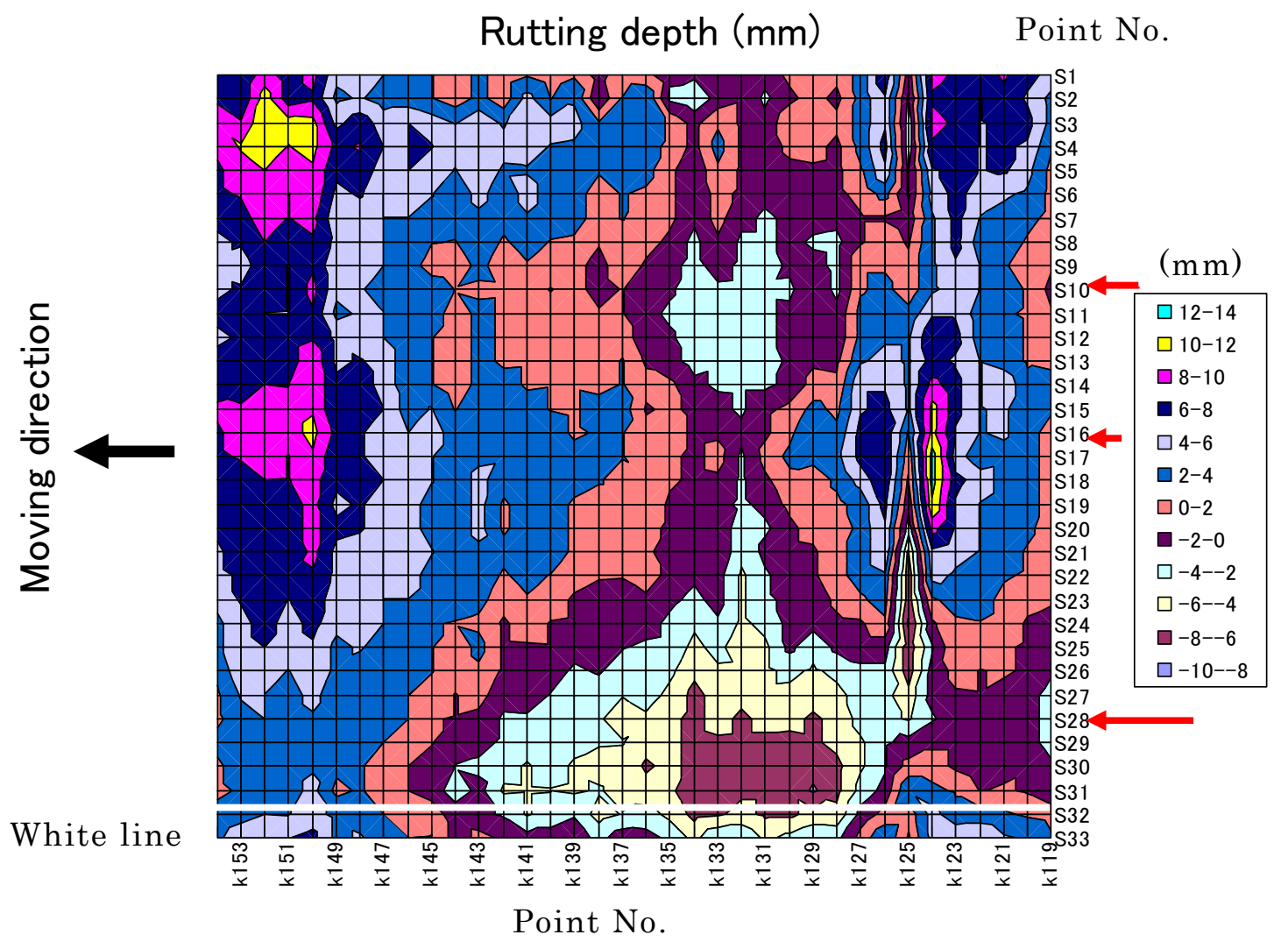

Fig. 12. Local rutting depth after two years later 


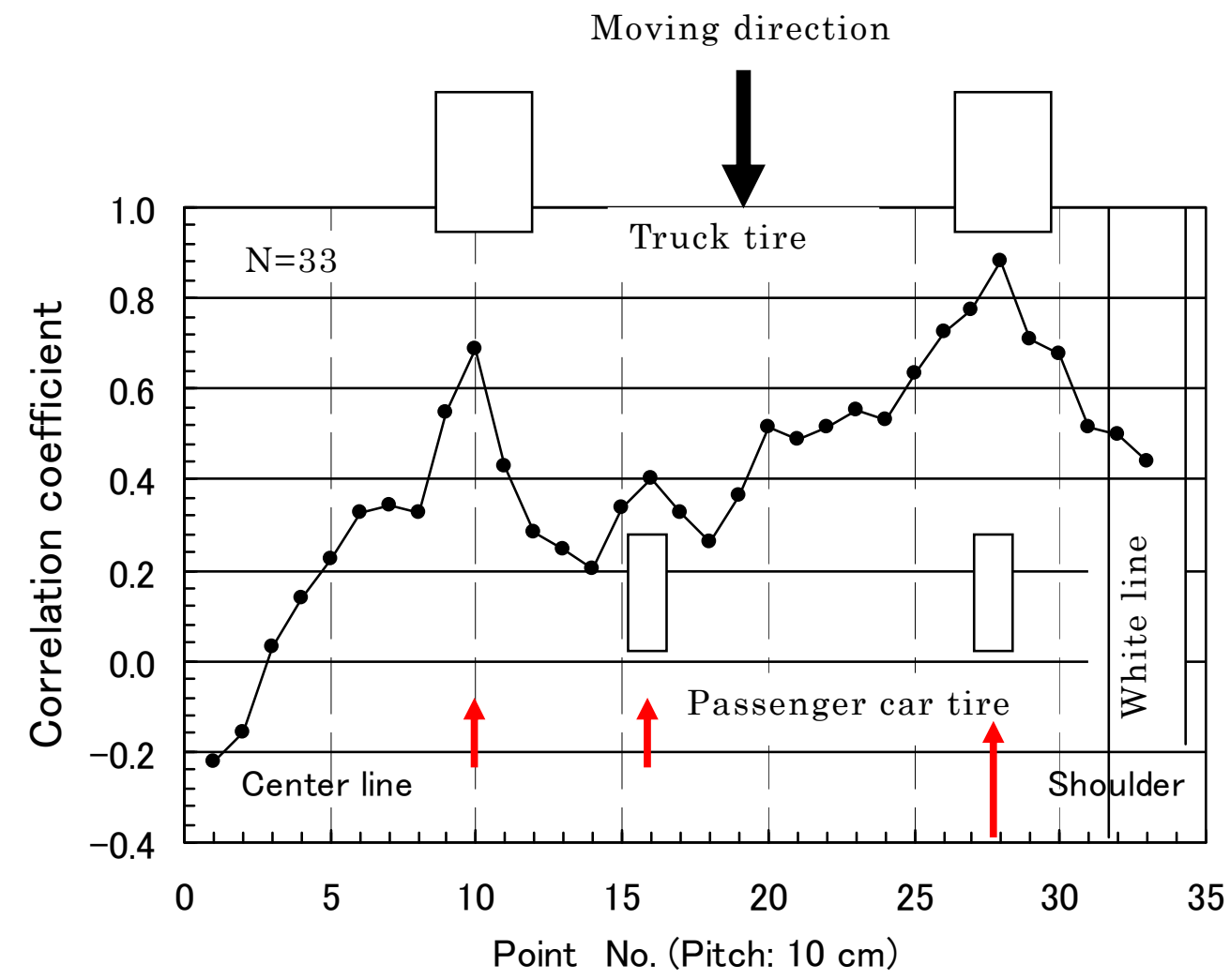

Fig. 13. The correlation coefficient between local temperature and local rutting 